\title{
Genomanalyse beim landwirtschaftlichen Nutztier
}

Teil 1: Molekularbiologische Analysen zur Vererbung der Leisten- und Hodensackbrüche beim Schwein

Teil 2: Der 37-kDa/67-kDa Lamininrezeptor (Precursor) im Interspeziesvergleich

\author{
Dissertation \\ zur Erlangung des Doktorgrades \\ der Fakultät für Agrarwissenschaften \\ der Georg-August-Universität Göttingen
}

\author{
vorgelegt von \\ Julia Beck \\ geboren in Kassel
}

Göttingen, Februar 2008 
D 7

1. Referent: Prof. Dr. Dr. Bertram Brenig

2. Referent: Prof. Dr. Christoph Knorr

Tag der mündlichen Prüfung: 31.01.2008 



\begin{abstract}
The thesis is divided into two parts. The studies presented in the first part describe the results of molecular analyses on the inheritance of congenital inguinal and scrotal hernia in the pig. The second part covers data on the comparative genomic analysis of the bovine and porcine $37-\mathrm{kDa} / 67-\mathrm{kDa}$ laminin receptor (precursor).

Inguinal/scrotal hernias in pigs are related congenital defects. With a frequency of 1-3\% in German pig populations these defects cause economic losses of $\sim 9,200,000 €$ per year. Therefore, the elucidation of the mode of inheritance and the development of genetic test assays are of great scientific and economic concern. Our studies on the genetic basis of the defect take place within the national research project „Entwicklung von Techniken und Methoden zur Kartierung von Defektgenen beim Schwein“.

The publications consolidated in this thesis describe the characterization of the porcine $\beta$-Glucuronidase gene (GUSB) and the porcine hyaluronidase gene cluster. Furthermore, 16 additional functional candidate genes were mapped to porcine chromosomes. Together with the results of a genomewide linkage scan, which was carried out at the Institute of Veterinary Medicine 11 of the 16 functional candidate genes could also be indentified as positional candidates. Three single nucleotide polymorphisms (SNPs) were characterized within the coding region of GUSB. Association analyses with these SNPs excluded the involvement of GUSB in the inheritance of inguinal/scrotal hernia. In addition to the genetic analyses calcium contents in samples of the peritoneum and the processus vaginalis of herniated piglets were determined and compared to samples of normal controls. Significant differences in calcium contents were found, pointing to the possible involvement of intracellular calcium contents and a perturbed apoptotic cascade on the development of inguinal/scrotal hernia.

The $37-\mathrm{kDa} / 67-\mathrm{kDa}$ laminin receptor (precursor) (LRP/LR) was previously identified as a receptor for the infectious prion protein $\left(\mathrm{PrP}^{\mathrm{Sc}}\right)$ and plays an important role in the internalization of $\operatorname{PrP}^{\mathrm{Sc}}$. Different affinities of the receptor might contribute to differences of the pathogen susceptibility of different species. The coding sequences of porcine and bovine LRP/LR genes were sequenced and compared. An amino acid difference within the indirect $\mathrm{PrP}^{\mathrm{Sc}}$ binding domain was detected, which might contribute to the resistance of pigs against orally administered $\operatorname{PrP}^{\mathrm{Sc}}$. Furthermore, several LRP/LR pseudogenes in both bovine and porcine genomes were characterized and described.
\end{abstract}




\section{Zusammenfassung}

Die vorliegende Arbeit ist in zwei Teile gegliedert. Der erste Teil stellt die Ergebnisse der molekularbiologischen Untersuchung der Vererbung der Leisten- und Hodensackbrüche (Hernia i/s) beim Schwein dar. Der zweite Teil umfasst Arbeiten zur vergleichenden molekulargenetischen Untersuchung des Lamininrezeptorgens bei Rind und Schwein.

Bei Hernia i/s des Schweins handelt es sich um einen kongenitalen Defekt, der mit einer Frequenz von 1-3\% in den deutschen Schweinepopulationen auftritt und wirtschaftliche Schäden von ca. 9.200.000 € im Jahr verursacht. Die Aufklärung der Vererbung des Defekts und schließlich die Entwicklung eines Gentest sind deshalb von großem wissenschaftlichem und wirtschaftlichem Interesse. Die molekulargenetische Untersuchung der Hernia i/s erfolgt am Tierärztlichen Institut im Rahmen des Forschungsprojektes „Entwicklung von Techniken und Methoden zur Kartierung von Defektgenen beim Schwein“.

Im Rahmen der vorliegenden Arbeit erfolgte die Charakterisierung der genomischen Sequenzen des B-Glucuronidase-Gens (GUSB) und des HyaluronidaseGen-clusters. Außerdem wurden 16 weitere funktionelle Kandidatengene kartiert. Anhand der Ergebnisse dieser Kartierung und der Ergebnisse aus einer ebenfalls am Tierärztlichen Institut durchgeführten genomweiten Kopplungs- und Assoziationsanalyse erhielten elf dieser Kandidatengene den Status eines funktionellpositionellen Kandidatengens. Für GUSB wurden drei SNPs (SNP = single nucleotide polymorphism) innerhalb drei verschiedener Exons charakterisiert. Eine Beteiligung des GUSB an der Vererbung von Hernia i/s konnte für die untersuchte Population anhand eines Assoziationstests, der für zwei der SNP-Marker durchgeführt wurde, ausgeschlossen werden. Nachdem unterschiedliche Kalziumgehalte im peritonealen Gewebe und dem Gewebe des Processus vaginalis von Ferkeln mit Hernia i/s nachgewiesen werden konnten, werden verstärkt auch Kandidatengene in Betracht gezogen, die an der zellulären Kalziumhomöstase sowie der apoptotischen Kaskade beteiligt sind.

Für den Lamininrezeptor (Precursor) (LRP/LR) wurde bereits eine essentielle Bedeutung für die Aufnahme von infektiösem Prion Protein $\left(\mathrm{PrP}^{\mathrm{Sc}}\right)$ in Zellen nachgewiesen. Unterschiedliche Bindungsaffinitäten des LRP/LR verschiedener Empfänger-Spezies zu $\mathrm{PrP}^{\mathrm{Sc}}$ von verschiedenen Donor-Spezies könnten zur Speziesbarriere der Übertragung der Transmissiblen Spongiformen Enzephalopathie (TSE) beitragen. Schweine entwickeln nach oraler Verabreichung von BSEinfiziertem Hirnmaterial keine TSE. Durch Vergleich von LRP/LR-kodierenden Sequenzen des Schweins und des Rinds konnten Unterschiede in der indirekten PrPBindungsdomäne des porcinen Rezeptors aufgedeckt werden, die eine verminderte Erregeraufnahme im Darm von Schweinen bedingen könnten. Außerdem wurden LRP-Pseudogene in den Genomen von Rind und Schwein isoliert und charakterisiert. 


\section{Liste der Publikationen}

Die vorliegende Arbeit basiert auf den durch Fettdruck hervorgehobenen Publikationen:

1. Beck, J., Knorr, C., Habermann, F., Fries, R. \& Brenig, B. (2002): Assignment of the beta-glucuronidase (GUSB) gene to porcine chromosome SSC3p16-->p14 by FISH and confirmation by hybrid panel analyses. Cytogenet Genome Res, 97:277G.

2. Brenig, B., Beck, J., Hall, A.J., Broad, T.E., Chowdhary, B.P. \& Piumi, F. (2004): Assignment of the equine solute carrier 26A2 gene (SLC26A2) to equine chromosome 14q15-$>$ q21 (ECA14q15-->q21) by in situ hybridization and radiation hybrid panel mapping. Cytogenet Genome Res, 107:139.

3. Chen, K.F., Beck, J., Huang, L.S., Knorr, C. \& Brenig, B. (2004): Assignment of the phosphoglycerate kinase $1(P G K 1)$ gene to porcine chromosome Xq12-q13 by fluorescence in situ hybridization and hybrid panel analyses. Anim Genet, 35:143-145.

4. Chen, K.F., Beck, J., Huang, L.S., Knorr, C. \& Brenig, B. (2004): Assignment of the phosphoglycerate kinase 2 (PGK2) gene to porcine chromosome 7q14-q15 by fluorescence in situ hybridization and by analysis of somatic cell and radiation hybrid panels. Anim Genet, 35:71-72.

5. Gatphayak, K., Knorr, C., Beck, J. \& Brenig, B. (2004): Molecular characterization of porcine hyaluronidase genes 1, 2, and 3 clustered on SSC13q21. Cytogenet Genome Res, 106:98-106.

6. Germerodt, M., Knorr, C., Beck, J., Drögemüller, C., Williams, J.L., Habermann, F., Fries, R. \& Brenig, B. (2004): Characterization and chromosome localization of a processed pseudogene related to the bovine laminin receptor gene family. Cytogenet Genome Res, 107:123-127.

7. Beck, J., Chowdhary, B.P. \& Brenig, B. (2005): Assignment of the equine colony stimulating factor 1 receptor gene $(C S F 1 R)$ to equine chromosome 14q15-->q16 (ECA14q15-->q16) by in situ hybridization and radiation hybrid panel mapping. Cytogenet Genome Res, 109:533.

8. Knorr, C., Beck, J., Beuermann, C., Chen, K., Ding, N., Gatphayak, K., Huang, L.S., Laenoi, W. \& Brenig, B. (2006): Chromosomal assignment of porcine oncogenic and apoptopic genes CACNA2D2, TUSC4, ATP2A1, COL1A1, TAC1, BAK1 and CASP9. Anim Genet, 37:523-525.

9. Beck, J., Bornemann-Kolatzki, K., Knorr, C., Täubert, H. \& Brenig, B. (2006): Molecular characterization and exclusion of porcine $G U S B$ as a candidate gene for congenital hernia inguinalis/scrotalis. BMC Vet Res, 2:14.

10. Knorr, C., Beuermann, C., Beck, J. \& Brenig, B. (2007): Characterization of the porcine multicopy ribosomal protein $\mathrm{SA} / 37-\mathrm{kDa}$ laminin receptor gene family. Gene, 395:135143.

11. Beuermann, C., Germerodt, M., Beck, J., Brenig, B. \& Knorr, C. (2008): Chromosomal assignment of eight porcine genes involved in apoptosis. Anim Genet 39.

12. Beuermann, C., Beck, J., Schmelz, H., Dunkelberg, E., Schütz, E., Brenig, B. \& Knorr, C. (2007): Total calcium content differences in tissues of piglets with hernia inguinalis/scrotalis and cryptorchidism. J Animal Science, eingereicht im Dezember 2007. 
$\begin{array}{ll}\text { Zusammenfassung } & \text { II }\end{array}$

\begin{tabular}{ll|l} 
Liste der Publikationen & III
\end{tabular}

1 EINLEITUNG $\quad 8$

2 MOLEKULARBIOLOGISCHE ANALYSEN ZUR VERERBUNG DER LEISTEN- UND HODENSACKBRÜCHE BEIM SCHWEIN

2.1 Krankheitsbild, Heritabilität, Vererbung und Frequenz

$\begin{array}{lll}2.2 & \text { Hypothesen zur Entstehung } & 11\end{array}$

2.2.1 Störung der transabdominalen Migration der Hoden 13

2.2.2 Störung der transinguinalen/inguinoskrotalen Migration der Hoden 15

2.2.3 Störung des Verschlusses des Processus vaginalis 16

$\begin{array}{llr}2.3 & \text { Darstellung des Forschungsprojektes } & 18\end{array}$

2.4 Diskussion und Ausblick für das Gesamtprojekt 21

2.4.1 Die positionelle Klonierung komplexer Erkrankungen 21

2.4.2 Positionelle Klonierung für Hernia inguinalis/scrotalis? 23

2.4.3 Funktionelle Kandidatengene - Back to the future? 26

3 DER 37-KDA/67-KDA LAMININREZEPTOR (PRECURSOR) IM INTERSPEZIESVERGLEICH 29

$\begin{array}{llr}3.1 & \text { Transmissible Spongiforme Enzephalopathien }\end{array}$

$\begin{array}{lll}\text { 3.2 Der 67kDa/37kDa Lamininrezeptor (Precursor) } & 31\end{array}$

$\begin{array}{llr}3.3 & \text { Die Speziesbarriere } & 34\end{array}$

3.4 Darstellung des Forschungsprojektes $\quad 36$

$\begin{array}{lll}3.5 & \text { Diskussion und Ausblick } & 37\end{array}$

4 LITERATURVERZEICHNIS $\quad 39$ 


\section{Einleitung}

Seit Beginn der Domestikation vor etwa 10.000 Jahren versucht der Mensch Leistungsmerkmale der Haustiere zu beeinflussen (Knorr, 2005). Die seit den 1970er Jahren entwickelten Methoden und Techniken der molekularen Genomanalyse sollen in der tierzüchterischen Anwendung den Selektionserfolg weiter steigern. Besonders für Merkmale mit geringer Heritabilität, für die mit den klassischen Verfahren der Zuchtwertschätzung und quantitativen Genetik nur ein geringer Zuchtfortschritt erzielt werden kann, versprechen die Entwicklung und Anwendung von direkten Gentests, der markergestützten Selektion (van der Werf und Kinghorn, 2000) und des Konzepts der genombasierten Selektion (Meuwissen et al., 2001) eine effektivere züchterische Einflussnahme.

Für die Entwicklung molekulargenetischer Selektionsverfahren kommt einerseits die direkte Identifizierung der kausalen Genvariante in einem Kandidatengenansatz zur Anwendung. Andererseits kann die Lokalisierung von QTL (quantitative trait loci) und komplex vererbten Erkrankungen mittels eng gekoppelter Marker erfolgen.

Solange das kausale Gen noch nicht identifiziert ist, kann auch die markergestützte Selektion in der jeweiligen Population zur Anwendung kommen. Durch die Selektion mit Hilfe direkter Gentests ist jedoch ein größerer Selektionserfolg zu erwarten als durch die markergestützte Selektion, da letztere mit geringerer Genauigkeit verbunden ist. Außerdem bleiben Markertests auf die Familien/Populationen beschränkt, in denen sie kartiert wurden, da Kopplungsphasen zwischen Familien/Populationen variieren können (Lande und Thompson, 1990). Deshalb sollte die Entwicklung von direkten Gentests als populationsunabhängig nutzbare Selektionswerkzeuge das Ziel der molekulargenetischen Untersuchung von Leistungsmerkmalen und Erbkrankheiten des landwirtschaftlichen Nutztiers sein.

Im Rahmen eines vom BMBF und FBF geförderten nationalen Projektes „Entwicklung von Techniken und Methoden zur Kartierung von Defektgenen beim Schwein“ wurden für vier Anomalienkomplexe - Afterlosigkeit, Gesäugeanomalien, Leisten- und Hodensackbrüche sowie Spreizer - molekulargenetische Analysen zur Aufklärung ihrer Vererbung durchgeführt. Am Tierärztlichen Institut wurde der Merkmalskomplex Leisten- und Hodensackbrüche bearbeitet. 
Der zweite Teil der vorliegenden Arbeit stellt Untersuchungen vor, in denen die Methoden der Genomanalyse zum Zwecke der Aufklärung von speziesspezifischen Unterschieden in der Empfänglichkeit gegenüber dem infektiösen Agens der Transmissiblen Spongiformen Enzephalopathien $\left(\mathrm{PrP}^{\mathrm{Sc}}\right)$ angewendet wurden. Die kodierenden Sequenzen des Lamininrezeptors (Precursors) (LRP/LR) von Rind und Schwein wurden verglichen, um zu untersuchen, ob strukturelle Unterschiede in den Genen die Resistenz des Schweins gegenüber oraler Erregerexposition erklären können. Die vergleichenden genomanalytischen Untersuchungen tragen hier zum grundsätzlichen Verständnis der zellulären Aufnahmemechanismen von PrPSc bei. 


\section{Molekularbiologische Analysen zur Vererbung der Leisten- und Hodensackbrüche beim Schwein}

\subsection{Krankheitsbild, Heritabilität, Vererbung und Frequenz}

Ein Leistenbruch (Inguinalhernie, Hernia inguinalis) liegt vor, wenn Eingeweide in den Leistenkanal vorfallen (Abbildung 2-1, B). Der Leistenbruch kann sich zum Hodensackbruch (Skrotalhernie, Hernia scrotalis) erweitern, wenn die Eingeweide bis in das Skrotum vordringen (Abbildung 2-1, C). Bei indirekten Inguinalund Skrotalhernien (Hernia $i / s$ ) handelt es sich um angeborene Defekte, da betroffene Tiere durch einen abnorm weiten Leistenkanal, vor allem aber durch einen nicht obliterierten Processus vaginalis (PV) bereits seit der Geburt prädisponiert sind (Clarnette und Hutson, 1999; Dahme und Weiss, 1999).

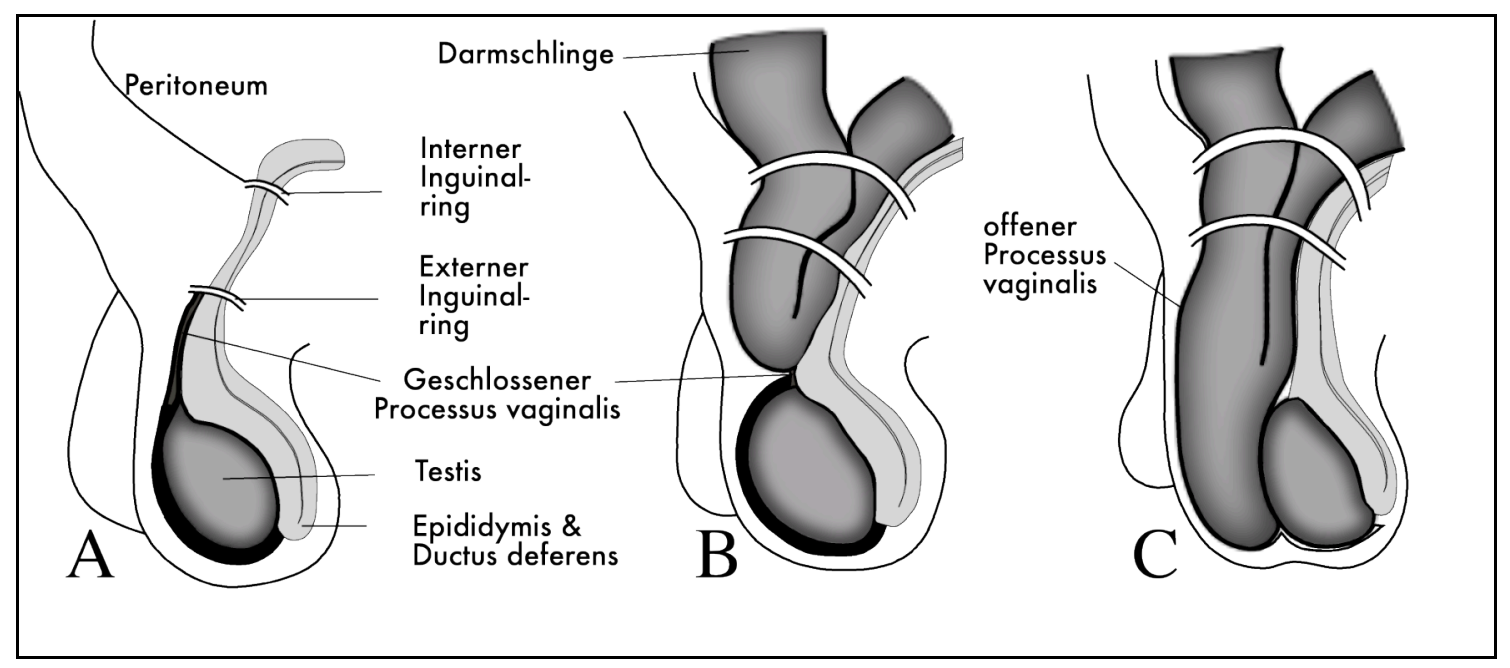

Abbildung 2-1: Darstellung eines normal verschlossenen Leistenkanals mit obliteriertem Processus vaginalis (PV) (A), einer indirekten Inguinalhernie mit abnorm weitem Leistenkanal, der PV ist lediglich distal obliteriert (B) und einer indirekten Skrotalhernie mit abnorm weitem Leistenkanal und vollständig offenem PV (C).

Des Weiteren weisen Hernia i/s eine eindeutig hereditäre Genese auf. Bereits 1926 konnte Warwick mit Hilfe von Rückkreuzungsexperimenten die Erblichkeit der Hernia i/s nachweisen (zitiert nach: Berge, 1941). Schätzwerte zur Heritabilität wurden darauf folgend mittels verschiedener Modelle und für verschiedene Schweinerassen bestimmt (vollständige Übersicht in Beißner, 2003). Althoff ermittelte die niedrigsten Schätzwerte $\left(h^{2}=0,022 \pm 0,006\right.$ bis $\left.0,035 \pm 0,007\right)$ in einem linearen Modell (Althoff, 
1985). Die höchsten Schätzwerte von $h^{2}=0,65 \pm 0,06$ und $0,86 \pm 0,16$ wurden von Mikami und Fredeen in zwei verschiedenen Herden ermittelt (Mikami und Fredeen, 1979).

Hernia $i / s$ werden wahrscheinlich oligo- oder polygen vererbt, jedoch sind in der Literatur widersprüchliche Hypothesen zum Vererbungsmodus des Defekts zu finden. Diese schließen sowohl monogene Erbgänge mit unvollständiger Dominanz als auch geschlechtsbegrenzte und polygen-quantitative Erbgänge ein (vollständige Übersicht in Beißner, 2003).

Hernien treten mit einer Frequenz von ungefähr $0,5 \%$ bis $1 \%$ in den deutschen Schweinepopulationen auf (Althoff et al., 1988). Knorr errechnete für die deutsche Schweineproduktion im Jahre 2003 unter Zugrundelegung einer 1\%igen Frequenz die Anzahl von 605.721 betroffenen Ferkeln und einen, allein durch die Behandlungskosten entstehenden, wirtschaftlichen Schaden von 9.291.760€ (Knorr, 2005).

\subsection{Hypothesen zur Entstehung}

Obwohl Inguinalhernien sowohl bei männlichen als auch bei weiblichen Absatzferkeln auftreten, zeigt sich bei den männlichen Tieren eine höhere Penetranz des Defekts. So traten in einer Studie (Heres, 1976) Brüche sechsmal häufiger bei männlichen als bei weiblichen Tieren auf (zitiert nach Beißner, 2003). In einer älteren Publikation berichtet der Autor, dass in 414 untersuchten Würfen männliche Tiere mit Skrotalhernien 1,99\%, weibliche Tiere mit Inguinalhernien dagegen nur 0,65\%, aller untersuchten Tiere ausmachten (Berge, 1941).

Mithin konzentrieren sich die meisten Untersuchungen zur Vererbung der Hernia i/s beim Schwein (Bornemann-Kolatzki, 2004; Grindflek et al., 2006) - die vorliegende Arbeit eingeschlossen - auf die Verhältnisse beim männlichen Tier.

Im Folgenden werden verschiedene Hypothesen zur Entstehung von Hernia i/s vorgestellt. Im Wesentlichen legen diese eine Störung des Hodenabstiegs (Descensus testis, DT) und/oder einen nicht erfolgten Verschluss des PV zugrunde. Abbildung 2-2 stellt den Abstieg der Hoden beim Schwein mit besonderem Augenmerk auf den PV und das Gubernaculum testis dar. 

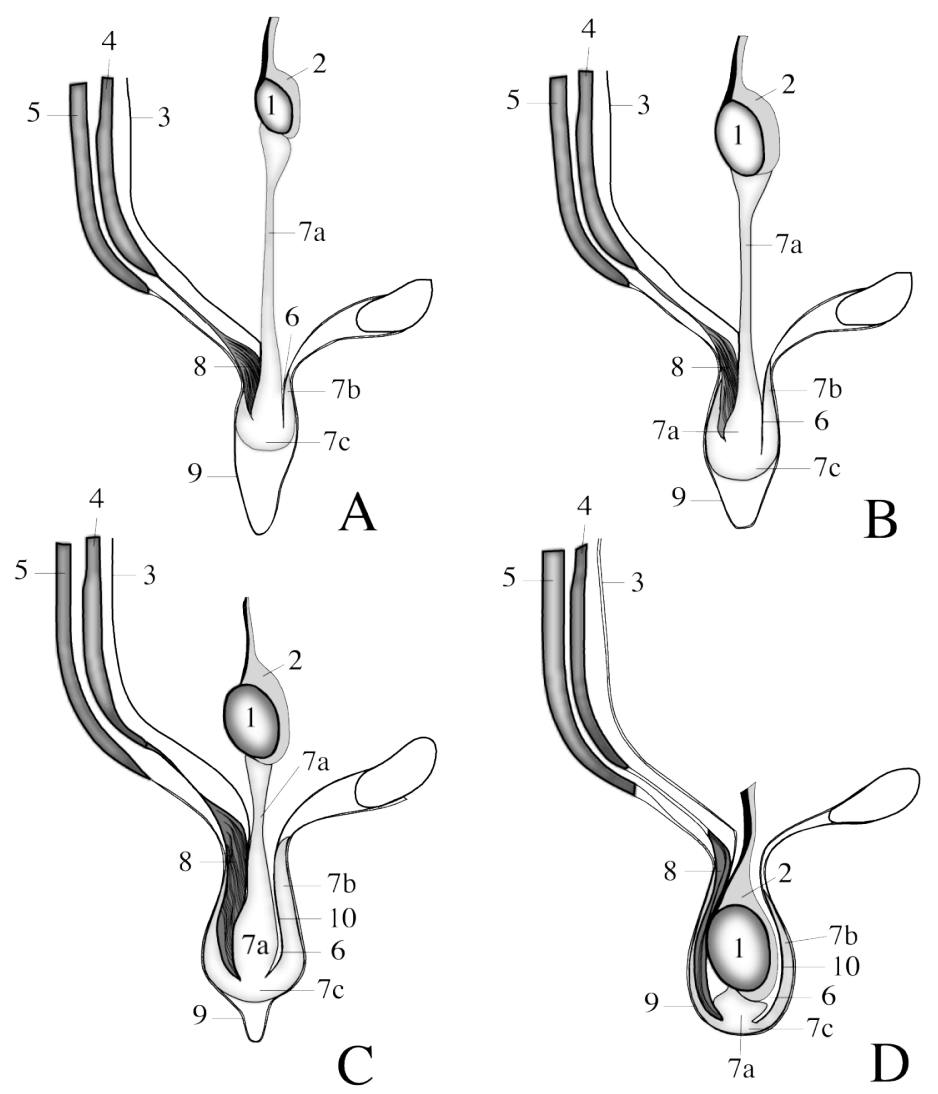

\begin{abstract}
Abbildung 2-2: Descensus testis beim Schwein (nach Wensing, 1986). (A) Entwicklung am Tag 65 post conceptionem (p.c.): Bis zum Beginn des DT entwickeln sich die Gonaden in der dorsalen Bauchhöhle. Das Gubernaculum testis beginnt sich zu entwickeln und wächst von der Bauchhöhle in das Skrotum. (B) 75 Tage p.c.: Das Gubernaculum testis beginnt sich zu verkürzen und zieht die Hoden in Richtung Skrotum. (C) 85-90 Tage p.c.: Kurz vor dem Durchtritt der Hoden durch den Leistenkanal beginnt sich das Gubernaculum testis stark zu verdicken und weitet damit den inneren und äußeren Inguinalring. Der Durchtritt der Hoden durch den Leistenkanal wird durch die Bildung des sackförmigen Processus vaginalis unterstützt. Der Hoden gleitet dabei in den Processus vaginalis. (D) Bei der Geburt: Das Gubernaculum testis, das schon während der Passage der Hoden durch den Leistenkanal abgeschwollen ist, bildet sich zum Hodenbändchen zurück. Der Processus vaginalis schließt sich und verödet. Die Abbildungen (A) und (B) stellen die transabdominale, (C) und (D) die inguinoskrotale Phase des DT dar.

1. Hoden; 2. Nebenhoden; 3. Parietales Blatt des Bauchfells; 4. Innerer schiefer Bauchmuskel; 5. Äußerer schiefer Bauchmuskel; 6. Processus vaginalis; 7a. Gubernaculum testis proper; 7b. vaginaler Teil des Gubernaculum testis; 7c. infravaginaler Teil des Gubernaculum testis; 8. Hodenheber; 9. Fascia spermatica; 10. Tunica vaginalis.
\end{abstract}

Der DT lässt sich in verschiedene Phasen untergliedern. Auf Hutson geht die Unterscheidung der transabdominalen und der inguinoskrotalen Phase des DT zurück, die in verschiedenen späteren Publikationen von anderen Autoren übernommen wurde (Hutson, 1985; Fentener van Vlissingen et al., 1988; Klonisch et al., 2004). Amann und 
Veeramachaneni stimmen der grundsätzlichen Gliederung nach Hutson zu, schlagen aber eine weitere Unterteilung der inguinoskrotalen Phase in eine transinguinale und eine inguinoskrotale Migration vor (Amann und Veeramachaneni, 2007).

Während der transabdominalen Phase des DT verlagern sich die Hoden von ihrer ursprünglichen Lage in der Nähe der Urnieren in die Leistengegend bis vor den späteren Leistenkanal. Mit der transinguinalen Migration wird der Durchtritt der Hoden und Nebenhoden durch die Bauchdecke beschrieben. Die Hoden passieren dabei den inneren und den äußeren Inguinalring und befinden sich mit Abschluss der transinguinalen Passage in einer subkutanen (s.c.) Position. Die inguinoskrotale Phase umfasst die Migration der s.c. positionierten Hoden in ihre endgültige Lage im Skrotum (Amann und Veeramachaneni, 2007).

Während der Verlauf des DT und damit auch die Unterscheidung der drei Phasen der Migration in allen Haus-, Nutz- und Labortierarten sowie beim Menschen ähnlich sind, verödet der PV bei Nagetieren und Kaninchen nicht. Dagegen erfolgt die Obliteration des PV und der feste Verschluss des Leistenkanals beim Menschen, Schwein, Rind und Pferd (Williams und Hutson, 1991).

\subsubsection{Störung der transabdominalen Migration der Hoden}

Während der transabdominalen Phase stimuliert das in den Leydig-Zellen (auch Leydigsche Zwischenzellen) der Hoden gebildete insulin-like peptide hormone (INSL3, auch: insulin-like factor 3 oder relaxin-like factor) das Wachstum der mesenchymalen Zellen des Gubernaculum testis (Adham et al., 1993). In transgenen Insl3 ${ }^{-/-}$-Mäusen bleiben die Gubernacula testis unterentwickelt und klein, die Hoden verbleiben in ihrer ursprünglichen Position in der Bauchhöhle (Nef und Parada, 1999; Zimmermann et al., 1999). Des Weiteren zeigen Mäuse mit Mutationen im INSL3-Rezeptor Lrg8-Gen (auch Great) sowie $\operatorname{Lrg} 8^{-/-}$-Mäuse denselben Phänotyp wie auch die Insl3 ${ }^{-/-}$-Tiere (Overbeek et al., 2001; Bogatcheva et al., 2003; Tomiyama et al., 2003).

Der Wirkungsweise des HOXA10-Gens auf die Ausbildung des Gubernaulum

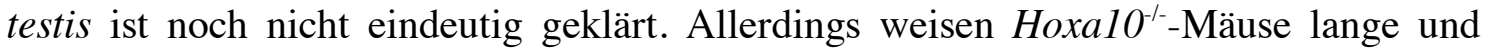
dünne Gubernacula testis und ebenfalls abdominal lokalisierte Hoden auf (Rijli et al., 1995; Satokata et al., 1995).

In den dargestellten Mausmodellen der gestörten abdominalen Migration treten keine Hernia $i / s$ auf. Für ätiologische und genetische Überschneidungen zwischen 
Kryptorchismus und Hernia i/s spricht jedoch die von verschiedenen Autoren festgestellte positive Korrelation der beiden angeborenen Defekte beim Schwein (Mikami und Fredeen, 1979; Knap, 1986; Liu, 1991; Beißner, 2003). Auch für den Menschen beschreiben verschiedene Autoren, dass Hernia i/s häufig, wenn auch nicht zwangsläufig, in Assoziation mit Kryptorchismus auftreten (Donnell et al., 1995; Barthold und Redman, 1996; Davey, 1997). In einer jüngeren Studie zur additivgenetischen Korrelation der beiden Defekte beim Schwein wurden große rassenspezifische Unterschiede gefunden, nämlich eine nur geringe positive additivgenetische Korrelation für die Rasse Pietrain $\left(\mathrm{r}_{\mathrm{g}}=0,121\right)$ und dagegen eine negative Korrelation mittlerer Größe $\left(r_{g}=-0,392\right)$ für die Deutsche Landrasse (Beißner, 2003). Aufgrund der physiologischen Zusammenhänge ist davon auszugehen, dass beide Anomalien auf einen gestörten DT zurückzuführen sind. Andererseits deuten die zum Teil stark unterschiedlichen und sogar widersprüchlichen Schätzwerte der genetischen Korrelation darauf hin,

a) dass keiner der Defekte auf einen einzigen genetischen Hintergrund zurückzuführen ist, d.h., dass mehrere Mutationen in verschiedenen Genen auf jeweils beide Defekte wirken und die Kombination der Mutationen auch zwischen Rassen oder sogar Familien variieren kann (Heterogenie),

b) dass Gene, die in unterschiedlichen Phasen des DT wirken, nicht unbedingt mit der Ausprägung beider Phänotypen in Zusammenhang stehen

c) und dass aber derselbe Genort Einfluss auf die Ausprägung entweder von Kryptorchismus und/oder Hernia $i / s$ haben kann.

Die Gene, die ausschließlich während der transabdominalen Migration der Hoden wirken (z.B. INSL3 und HOXA10), stellen aufgrund der oben beschriebenen Wirkung der Genprodukte schwächere Kandidaten für den Phänotyp Hernia i/s als für den Phänotyp transabdominaler Kryptorchismus dar. So bestätigen auch Assoziationsstudien der beiden Gene beim Schwein, dass HOXA10 und INSL3 an der Ausbildung des Phänotyps Hernia i/s zumindest in der jeweils untersuchten Population nicht beteiligt sind (Uibeleisen, 2001; Knorr et al., 2004).

Wahrscheinlicher erscheint dagegen die Möglichkeit, dass eine verzögerte inguinoskrotale Migration der Hoden $\mathrm{zu}$ einem nicht vollständig verschlossenem 
Leistenkanal bzw. einem nicht obliteriertem PV und damit zur anschließenden Ausbildung der Hernia $i / s$ führt. Hernia $i / s$ können also auch als Folge von transinguinalem Kryptorchismus auftreten (Davey, 1997; Amann und Veeramachaneni, 2007).

\subsubsection{Störung der transinguinalen/inguinoskrotalen Migration der Hoden}

Gegen Ende des normalen transabdominalen Abstiegs befinden sich die Hoden in der Leistengegend vor dem Leistenkanal. Während einer Pausenphase vor dem Beginn der transinguinalen Migration wird der Leistenkanal mit dem inneren und äußeren Inguinalring durch die Verdickung des Gubernaculum testis geweitet. Dazu nimmt das Gubernaculum testis durch die Einlagerung von Wasser in das Gewebe schnell an Masse zu (Heyns et al., 1986; Heyns et al., 1990). Die massive Wassereinlagerung wird durch die Bildung von Glycosaminoglycanen (vor allem Hyaluronan) erreicht (Fentener van Vlissingen et al., 1989). Gleichzeitig verringert sich die Größe der Hoden, um die Passage durch den Leistenkanal zu ermöglichen. Der zunehmende intraabdominale Druck schiebt die Hoden schließlich durch den Leistenkanal (Wensing, 1988; Hutson et al., 1997).

Die Regression des Gubernaculum testis beginnt in der inguinoskrotalen Phase des DT mit dem Katabolismus des Hyaluronan, das durch die drei Enzyme Hyaluronidase (HYAL), B-N-Acetylglucosaminidase (HEXB) und B-Glucuronidase (GUSB) abgebaut wird (Fentener van Vlissingen et al., 1989). Ein Funktionsverlust eines oder mehrerer dieser Enzyme kann eine übermäßige Verdickung und/oder ein verzögertes Abschwellen des Gubernaculum testis bewirken und damit die persistierende Weitung des Leistenkanals bedingen, die männliche Ferkel für die Ausbildung einer Hernia i/s prädisponiert. Die Publikationen Beck et al. (2006) und Gatphayak et al. (2004) stellen die im Rahmen der vorliegenden Arbeit durchgeführten molekulargenetischen Analysen der Kandidatengene GUSB und HYAL vor.

Die Sekretion von Testosteron in den Leydig-Zellen der Hoden ist von entscheidender Bedeutung für den inguinoskrotalen Abstieg der Hoden, hat aber keine Wirkung auf die beiden anderen Phasen des DT (Heyns et al., 1986; Fentener van Vlissingen et al., 1988; Fentener van Vlissingen et al., 1989; Heyns et al., 1990). 
Experimente mit dem Antiandrogen Flutamid, das zu verschiedenen Zeitpunkten der Gestation verabreicht wurde, geben weiteren Aufschluss über die Wirkung des Testosterons. McMahon und Kollegen konnten an porcinen Feten zeigen, dass Testosteron aber nicht direkt während der inguinoskrotalen Phase wirkt, sondern führt bereits während der transabdominalen Phase zur Maskulinisierung des genitofemoralen Nervs (GFN) (McMahon et al., 1995; zur Übersicht: Amann und Veeramachaneni, 2007).

Nach erfolgreicher Maskulinisierung des GFNs schüttet dieser dann während der inguinoskrotalen Migration das calcitonin gene-related peptide (CGRP, auch $\alpha$ CGRP) aus. Die CGRP Signale bewirken die direktionale Steuerung des Wachstums des Gubernaculum testis zum Boden des Skrotums. An der Spitze des Gubernaculum testis wurden entsprechend CGRP-Rezeptoren nachgewiesen (Hutson et al., 1998; Hutson und Hasthorpe, 2005; Ng et al., 2005). Das CGRP entsteht durch alternatives splicing aus der Calcitonin-mRNA (CALCA) (Rosenfeld et al., 1983).

Aufgrund der essentiellen Bedeutung des Testosterons für den Hodenabstieg könnten auch Defekte der Gene GnRH und GnRHR (gonadotropin releasing hormone und gonadotropin releasing hormone receptor), LH und LHR (luteinizing hormone und luteinizing hormone receptor) sowie des AR (androgen receptor) an der Entstehung von Kryptorchismus und Hernia i/s beteiligt sein (Hutson et al., 1997; El-Gehani et al., 1998; Klonisch et al., 2004; Amann und Veeramachaneni, 2007).

\subsubsection{Störung des Verschlusses des Processus vaginalis}

Die nicht erfolgte Obliteration des PV gilt sowohl bei Buben und Mädchen als Prädisposition für die Ausbildung einer Inguinalhernie (Clarnette et al., 1998). Der Verschluss des PV erfolgt bei männlichen Individuen nur, wenn die Hoden ihre endgültige Lage im Skrotum erreicht haben (Barthold und Redman, 1996).

Der humane PV verödet während des ersten Lebensjahres. Als Auslöser vermutet man den postnatalen Anstieg des Testosteronspiegels, der in den ersten Lebensmonaten erfolgt (Hadziselimovic et al., 1986).

Eine jüngst veröffentlichte Studie, in der die Assoziation von Polymorphismen des CAG-repeats im Exon 1 des $A R$ mit dem Phänotyp unilateraler Kryptorchismus und kontralateral offener PV festgestellt wurde, untermauert die Bedeutung der Androgene 
und des $A R$ für den DT einerseits und den Verschluss des PV andererseits (Silva-Ramos et al., 2006).

Der Hypothese folgend, dass Androgene die Ausschüttung von CGRP durch den GFN bedingen, untersuchten Hutson und Kollegen die Wirkung von CGRP auf die Fusion des PV-Epithels an humanen Organkulturen. Die Ergebnisse dieser Untersuchung weisen darauf hin, dass es während der Obliteration des PV zu einer Transformation der Epithelzellen zu Fibroblasten kommt und diese Transformation durch CGRP induziert wird (Hutson et al., 2000).

Des Weiteren konnte gezeigt werden, dass die Wirkung von CGRP eine indirekte sein muss, da keine CGRP-Rezeptoren an den Epithelzellen des PV nachgewiesen werden konnten. So wurde auch die Wirkung des hepathocyte growth factors auf die Epithelzellen untersucht und eine positive Wirkung auf die Fusion des Gewebes nachgewiesen (Hutson et al., 2000).

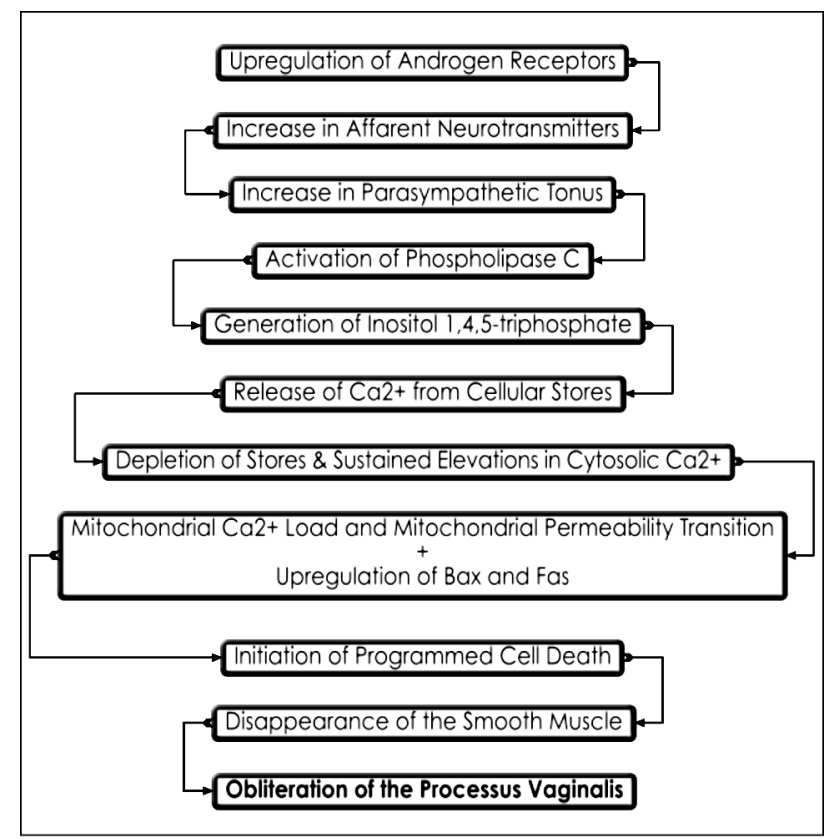

Abbildung 2-3: Ablaufschema zur Obliteration des Processus vaginalis nach erfolgtem Hodenabstieg (nach Tanyel, 2004).

Die meisten der bisher zitierten Autoren gehen davon aus, dass die Migration der Hoden passiv, also ohne jegliche muskuläre Beteiligung, erfolgt. Dagegen argumentiert Tanyel in jüngeren Publikationen, dass sich am PV glatte Muskelzellen bilden, die durch ihre Kontraktion das Gubernaculum testis, die Nebenhoden und die Hoden in das Skrotum befördern. Um die Obliteration des PV zu ermöglichen, müssen 
diese Muskelzellen nach erfolgtem Hodenabstieg der Apoptose unterliegen. Die Apoptose wird durch den Abfall des symphatischen nervalen Tonus, der wiederum androgenabhängig ist, eingeleitet (Tanyel, 2004; Tanyel und Okur, 2004). Eine Störung der in Abbildung 2-3 schematisch dargestellten Kaskade führt demzufolge zu einer persistierenden Öffnung des PV.

Die Hypothese, dass Kryptorchismus und Hernia $i / s$ phänotypische Erscheinungsbilder einer zugrunde liegenden Störung der Apoptose bestimmter Zelltypen darstellen, wird von anderen Autoren bestritten (Hutson et al., 2000; Hutson und Hasthorpe, 2005).

\subsection{Darstellung des Forschungsprojektes}

Die molekulargenetische Untersuchung von Hernia $i / s$ erfolgt am Tierärztlichen Institut im Rahmen des Forschungsprojektes „Entwicklung von Techniken und Methoden zur Kartierung von Defektgenen beim Schwein“, das durch den Förderverein Biotechnologieforschung der Deutschen Schweineproduktion e.V. finanziell sowie durch die Bereitstellung von Probenmaterial unterstützt wird. Zusätzlich wurden Teile des Projekts durch die Deutsche Forschungsgemeinschaft finanziell unterstützt.

Der Projektansatz umfasste in Phase 1 die Identifizierung von Chromosomenregionen, die mit dem Defekt assoziiert sind. Daneben wurden, zunächst noch ohne positionelle Informationen, funktionelle Kandidatengene kartiert und mittels SNP-Markern (SNP = single nucleotide polymorphisms) auf eine mögliche Assoziation zum Merkmal untersucht.

Zur positionellen Klonierung, der an der Vererbung von Hernia i/s beteiligten Chromosomenregionen, wurde ein Genomscan mit polymorphen DNA-Markern (DNA = desoxyribonucleic acid) und ein Genomic mismatch scanning, das auf der Isolierung von identical-by-descent-DNA beruht, durchgeführt (Bornemann-Kolatzki, 2004).

$\mathrm{Zu}$ den funktionellen Kandidatengenen der Phase 1 gehörten die Gene der Hyaluronan-abbauenden Enzyme (GUSB, HYAL, HEXB). Die Ergebnisse zu den Untersuchungen an GUSB und den Genen des $H Y A L$-Clusters sind in den Publikationen Beck et al. (2002), Gatphayak et al. (2004) und Beck et al. (2006) dargestellt. 
Des Weiteren wurden INSL3 und HOXA10 als funktionelle Kandidatengene untersucht und ihre Beteiligung an der Vererbung von Hernien anhand von Assoziationsstudien ausgeschlossen (Uibeleisen, 2001; Knorr et al., 2004). Die Gene $C A L C / C G R P$ und HEXB wurden kartiert. Beide Gene sind auf dem porcinen Chromosom 2 (SSC, Sus scrofa chromosome) lokalisiert (Knorr et al., 2002; Mueller et al., 2003).

Mit Abschluss des ersten Genomscans lagen erste Informationen zu den mit dem Defekt assoziierten Regionen auf SSC3, SSC6, SSC7, SSC12 und SSC15 vor (Bornemann-Kolatzki, 2004). Die Gene HYAL, HEXB, CALCA/CGRP konnten somit aufgrund ihrer Lokalisation außerhalb der assoziierten Regionen als Kandidaten zumindest für die untersuchte Population - ausgeschlossen werden, während sich das GUSB-Gen innerhalb der assoziierten Region auf SSC3 befindet.

In Phase 2 des Projekts, die bis zum heutigen Tag andauert, erfolgt einerseits die weitere Feinkartierung der assoziierten Chromosomenregionen, andererseits werden nunmehr mit Hilfe der positionellen Daten und unter Zuhilfenahme von komparativen Genkarten solche Kandidatengene zur weiteren Analyse ausgewählt, die funktionell mit dem Defekt in Verbindung stehen könnten und in einer der assoziierten Chromosomenregionen lokalisiert sind.

Das Vorgehen umfasst dabei die Auswahl funktioneller Kandidatengene anhand der in Kapitel 2.2 vorgestellten physiologischen Zusammenhänge sowie eigener Untersuchungen zur Physiologie des Verschlusses des PV (Beuermann et al., 2007) und die anschließende molekulargenetische Kartierung der Gene. Funktionelle Kandidatengene, die innerhalb einer der assoziierten Regionen lokalisiert sind, erhalten den Status eines funktionell-positionellen Kandidatengens und werden für weitergehende SNP-Analysen vorgesehen.

Zur Klasse der funktionellen Kandidatengene in Phase 2 gehören die Gene PGK2 (Phosphoglycerat-Kinase 2), CACNA2D2 (calcium channel, voltage-dependent, alpha-2/delta subunit 2), TUSC4 (tumor supressor candidate 4), ATP2A1 (ATPase, $\mathrm{Ca}^{2+}$-transporting, fast-twitch 1), COL1A1 (Kollagen, Typ 1, alpha 1), TAC1 (Tachykinin 1), BAK1 (BCL2-Antagonist killer 1), CASP9 (Kaspase 9). Von diesen erhielten ATP2A1, COL1A1, BAK1 und CASP9 nach erfolgter Kartierung den Status eines funktionell-positionellen Kandidatengens (Chen et al., 2004; Knorr et al., 2006). 
Mittels komparativer Genkarten wurden weitere Gene der apoptotischen Kaskade innerhalb der mit den Hernia $i / s$ assoziierten Genomregionen identifiziert, die Lokalisation dieser Gene konnte anschließend durch Radiation-Hybrid-Panel-Analysen bestätigt werden (Beuermann et al., 2008). Während nach der Typisierung eines SNPMarkers und anschließender Assoziationsanalyse die Beteiligung von ATP2Al an der Vererbung von Hernia i/s bereits ausgeschlossen werden konnte (unveröffentlichte Ergebnisse), dauern die Untersuchungen an den anderen genannten Genen noch an. 


\subsection{Diskussion und Ausblick für das Gesamtprojekt}

Die vorliegende Arbeit stellt Ergebnisse aus der molekulargenetischen Analyse von Kandidatengenen für die Defekte Hernia $i / s$ und aus physiologischen Untersuchungen zum Verschluss des PV beim Schwein vor. Daneben wurde im Rahmen des Gesamtprojektes auch ein QTL-Scan durchgeführt.

\subsubsection{Die positionelle Klonierung komplexer Erkrankungen}

Mit QTL wird ein Genlocus (bzw. ein Cluster eng gekoppelter Loci) bezeichnet, dessen Varianten (QTL-Allele) zu unterschiedlichen Messwerten eines oder mehrerer multifaktoriell bedingter, quantitativer Merkmale führen (Definition wörtlich übernommen aus: Geldermann, 2005). Mit Blick auf die multifaktorielle Vererbung der Hernia i/s sprechen verschiedene Autoren von QTL-Studien (Ding, 2006; Grindflek et al., 2006), auch wenn es sich bei den Hernia i/s um ein qualitativ betrachtetes Merkmal handelt.

In der Humanmedizin wird zur Beschreibung komplexer Vererbungsmodelle der Begriff der genetischen komplexen Erkrankung (complex disease) verwendet.

Die komplexen Erkrankungen sind durch die folgenden Merkmale gekennzeichnet:

a) Es besteht unvollständige Penetranz, d.h. nicht alle prädisponierten/empfänglichen Individuen erkranken tatsächlich.

b) An der Vererbung sind mehrere Genorte beteiligt, von denen einige Hauptgenorte mit starken Effekten und andere Genorte mit schwachen Effekten auf die Ausprägung der Prädisposition wirken.

c) Die an der Vererbung beteiligten Genorte interagieren miteinander und/oder mit verschiedenen Umwelteffekten.

d) Es besteht Heterogenie.

Alle Merkmale der komplexen Erkrankung treffen auch auf die Defekte Hernia

$i / s$ zu. Aufgrund der komplexen Vererbung und Umweltinteraktionen ist es außerordentlich schwierig, die genetischen Grundlagen solcher Erkrankungen sowie der QTs (quantitative traits) aufzudecken.

In den 1980er Jahren wurden frühe Kopplungsanalysen anhand der Blutgruppenmarker durchgeführt, später kamen molekularbiologische Markersysteme 
wie zum Beispiel RFLP-Marker (RFLP = restriction fragment length polymorphism) und die Mikrosatelliten-Marker hinzu. Seitdem wurden verschiedene mendelnd vererbte monogene Erkrankungen, für die es zunächst keinerlei Hinweise auf funktionelle Kandidatengene gab, mit Hilfe von Kopplungsanalysen untersucht und die an ihrer Vererbung beteiligten Gene positionell kloniert (Collins, 1995; Risch, 2000). Diese Erfolge der positionellen Klonierungsstrategie führten dazu, dass in zunehmendem Maße versucht wurde auch die Genetik von QTs und komplexen Erkrankungen mittels positioneller Klonierung aufzuklären.

Für das Schwein wurden seit den 1990er Jahren insgesamt 1.675 QTL für verschiedene Merkmale in insgesamt 110 Publikationen veröffentlicht. Vor allem die wirtschaftlich interessanten Leistungsparameter wie Fleischqualität und Reproduktionsleistung der Sauen wurden umfangreichen QTL-Studien unterzogen (Tabelle 2-1).

Tabelle 2-1: Anzahl der für das Schwein beschriebenen QTL pro Merkmalsklasse (Quelle: PigQTLdb, NAGRP, 2007a)

\begin{tabular}{|c|c|c|}
\hline Merkmalsklasse & Beispielhafte Merkmale & Anzahl der QTL \\
\hline Exterieur & $\begin{array}{l}\text { Verhaltensmerkmale } \\
\text { Pigmentierung } \\
\text { Konformation } \\
\text { Defekte (z.B.Hernia i/s) }\end{array}$ & 50 \\
\hline Gesundheit & $\begin{array}{l}\text { Immunkapazität } \\
\text { Krankheitsresistenz }\end{array}$ & 15 \\
\hline Fleischqualität & $\begin{array}{l}\text { Durchschnittliche Rückenspeckdicke } \\
\text { Fettgehalt }(\%) \text { des Schlachtkörpers } \\
\text { Intramuskulärer Fettgehalt }\end{array}$ & 1283 \\
\hline Produktionsparameter & $\begin{array}{l}\text { Futteraufnahme } \\
\text { Futterverwertung } \\
\text { Wachstum }\end{array}$ & 258 \\
\hline Reproduktionsparameter & $\begin{array}{l}\text { Wurfgröße } \\
\text { Reproduktionsorgane (Zitzenzahl, Hodengewicht) } \\
\text { Gestationslänge }\end{array}$ & 67 \\
\hline
\end{tabular}

Allerdings konnte nur für eine Minderheit der QTL des Schweins und der humanen komplexen Erkrankungen eine kausale Mutation für den betrachteten Effekt identifiziert werden (Risch, 2000; Rothschild et al., 2007). Tatsächlich konnten ausgehend von QTL-Studien kausale Mutationen in nur drei Genen aufgedeckt werden. Namentlich handelt es sich um IGF2 (insulin-like growth factor 2, Nezer et al., 1999) für die Bemuskelung, CAST (calpastatin, Ciobanu et al., 2004) für Fleischzartheit und PRKAG3 (protein kinase, AMP-activated, noncatalytic, gamma-3, Milan et al., 2000) 
für Fleischqualität. Die zugrunde liegende Mutation des monogen vererbten Malignen Hyperthermie Syndroms des Schweins wurde ebenfalls durch positionelle Klonierung aufgedeckt (Fujii et al., 1991).

Der geringe Erfolg der QTL-Kartierung wird im Wesentlichen auf drei Gründe zurückgeführt. Erstens werden vor allem in Kopplungsanalysen beim landwirtschaftlichen Nutztier aufgrund der Verwendung von meist 300-700 Tieren aus experimentellen F2-Populationen häufig große QTL-Regionen nachgewiesen (Dekkers und Rothschild, 2007; Rothschild et al., 2007), da aufgrund der geringen Anzahl informativer Meiosen die Auflösung der Kopplungskarte gering bleibt (Wu et al., 2002). Nicht selten sind diese Regionen 20-40 cM groß (cM = Centimorgan, entspricht etwa einer Million Basenpaaren (Mbp)). Eine direkte positionelle Klonierung aus einer 20-40 Mbp großen genomischen Region ist jedoch unmöglich, da Regionen dieser Ausdehnung immer noch 1-2\% des gesamten Genoms abdecken und durchaus 200-400

positionelle Kandidatengene enthalten können (Schook et al., 2005; Dekkers und Rothschild, 2007).

Zweitens wird angeführt, dass besonders für QT und Defekte mit geringen Heritabilitäten (von $\leq 10 \%$ ) und relativ geringen Einzelgeneffekten, die untersuchten Tierzahlen oft nicht ausreichend groß sind und bis zu mehreren Tausend Tiere umfassen müssten (Thomson, 2001; Rothschild et al., 2007).

Drittens sind die Ergebnisse verschiedener QTL-Studien häufig inkonsistent, was die Identifizierung der kausalen Mutationen auch dann noch erschwert, wenn bereits positionelle Daten vorliegen (Risch, 2000; Rothschild et al., 2007).

\subsubsection{Positionelle Klonierung für Hernia inguinalis/scrotalis?}

Für die Defekte Hernia i/s wurden bisher Daten aus zwei genomweiten QTLScans veröffentlicht. In beiden Studien wurde neben einer initialen Kopplungsanalyse auch eine Assoziationsanalyse durchgeführt (Tabelle 2-2).

Die Ergebnisse der beiden Studien sind jedoch nur marginal deckungsgleich. Dies kann bedeuten, dass in den verschiedenen untersuchten Populationen verschiedene Gene an der Vererbung der Hernia $i / s$ beteiligt sind. Dass die multifaktorielle Vererbung der Hernia i/s in verschiedenen Populationen oder sogar verschiedenen Familien variiert, wird auch von Plastow und Kollegen beschrieben. Eine Assoziation 
der Hernia i/s mit zwei Markern in zwei verschiedenen Genomregionen konnte nur in einer der untersuchten PIC-Zuchtlinien nachgewiesen werden (Plastow et al., 2003).

In Anbetracht dieser Hinweise könnte für die weitere Feinkartierung der QTLRegionen eine klarere Stratifikation der gesammelten Proben nach Rassen und, wenn möglich, sogar nach Populationen (z.B. Gruppierung nach Zuchtstationen und innerhalb der Zuchtstationen nach Zuchtlinien) entscheidende Vorteile bringen.

Ähnliche Konzepte werden auch in der Humangenetik verfolgt, indem komplexe Erkrankungen zunächst in genetisch isolierten Bevölkerungsgruppen untersucht werden (Peltonen, 2000).

Tabelle 2-2: Vergleichende Darstellung der Ergebnisse aus zwei verschiedenen QTL-Studien für das Merkmal Hernia i/s beim Schwein

\begin{tabular}{|c|c|c|c|c|c|c|}
\hline Autor & $\begin{array}{l}\text { Genom- } \\
\text { regionen }^{1}\end{array}$ & Tiere & Marker & $\begin{array}{l}\text { Mittlerer } \\
\text { Marker- } \\
\text { abstand }\end{array}$ & $\begin{array}{l}\text { Rasse/ } \\
\text { Population }\end{array}$ & $\begin{array}{l}\text { Statistisches } \\
\text { Verfahren }\end{array}$ \\
\hline $\begin{array}{l}\text { Bornemann- } \\
\text { Kolatzki, } \\
2004\end{array}$ & $\begin{array}{l}\text { SSC3p17-p15 + } \\
\text { q25-q27 } \\
\text { SSC6q11-q26 } \\
\text { SSC7p11 } \\
\text { SSC12p14-p11 } \\
\text { SSC15q11-q21 }\end{array}$ & 512 & $\begin{array}{l}133 \text { Mikros. } \\
6 \text { SNPs }\end{array}$ & n.a. & $\begin{array}{l}\text { Pietrain } \\
\text { Deutsches } \\
\text { Edelschwein } \\
\text { Hampshire } \\
\text { Deutsche } \\
\text { Landrasse }\end{array}$ & $\begin{array}{l}\text { Nicht- } \\
\text { parametrische } \\
\text { Kopplungsanalyse } \\
\text { Single-point und } \\
\text { Multi-point }\end{array}$ \\
\hline $\begin{array}{l}\text { Grindflek et } \\
\text { al., } 2006\end{array}$ & $\begin{array}{l}\text { SSC1p25-q14 } \\
\text { SSC2p14-q23 } \\
\text { SSC5q11-q22 } \\
\text { SSC6q27-q32 } \\
\text { SSC7q11-q15 } \\
\text { SSC7q24-q26 } \\
\text { SSC15 } \\
\text { SSC17p11 und } \\
\text { p21 }\end{array}$ & 282 & 137 Mikros. & $17 \mathrm{cM}$ & $\begin{array}{l}\text { Norwegische } \\
\text { Landrasse + } \\
\text { Dänische } \\
\text { Landrasse }\end{array}$ & $\begin{array}{l}\text { Nicht- } \\
\text { parametrische } \\
\text { Kopplungsanalyse } \\
\text { Single-point und } \\
\text { Multi-point }\end{array}$ \\
\hline
\end{tabular}

${ }^{1}$ Aus Gründen der Übersichtlichkeit werden hier nur Regionen aufgeführt, die mittels Kopplunganalyse identifiziert wen, obwohl auch anschließende Assoziationsanalysen für die gleichen Marker durchgeführt wurden, die die Ergebnisse aus der Kopplungsanalyse z.T. bestätigten. Weiterhin wurden zur besseren Vergleichbarkeit der Ergebnisse die von Bornemann-Kolatzki angegeben cM-Intervalle in die Positionen der physikalischen Genomkarte übersetzt. Dies erfolgte mit Hilfe der unter http://www.animalgenome.org/pigs/maps/marcmap.html abrufbaren Chromosomenkarten (NAGRP, 2007b).

Die beschriebenen chromosomalen Regionen beider Studien sind noch zu groß, um eine direkte positionelle Klonierung der kausalen Gene und ihrer Mutationen zu ermöglichen. Deshalb wird am Tierärztlichen Institut im Moment an der weiteren Feinkartierung der gekoppelten Genomregionen gearbeitet. Außerdem werden die gekoppelten Marker in einer zweiten Stichprobe untersucht, um die Ergebnisse der ersten Kopplungsanalyse auch innerhalb einer weiteren Population zu überprüfen.

Die Typisierung von SNP-Markern und die anschließende Assoziationsanalyse eignen sich im besonderen Maße für die Feinkartierung. 
Während in der Kopplungsanalyse die Kosegregation zweier Marker oder eines Markers und eines Phänotyps innerhalb einer bestimmten Familienstichprobe betrachtet wird, betrachtet man in Assoziationsanalysen die Abweichung von der zufälligen Verteilung von Markerallelfrequenzen (linkage disequilibrium, LD) auf Ebene der Population.

Assoziationsanalysen haben im Vergleich zu Kopplungsanalysen eine größere statistische Aussagekraft (power) und benötigen deshalb deutlich kleinere Stichprobengrößen (Abbildung 2-4).

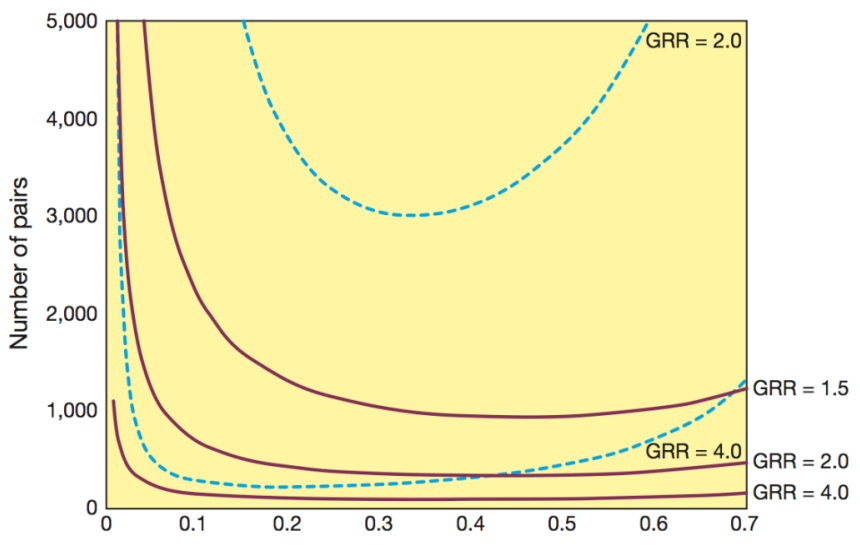

Abbildung 2-4: Vergleichende Darstellung der statistischen Aussagekraft der Kopplungsanalyse (gestrichelte Linien) und der Assoziationsanalyse (durchgezogene Linien) (übernommen aus Risch, 2000).

Kopplungsanalyse: für eine affected-sibpair-Stichprobe (ASP) unter Annahme von vollständiger Kopplung zwischen Marker und Merkmal.

Assoziationsanalyse: betrachtet den kausalen SNP. Die hier dargestellte Poweranalyse legt eine case-control-Stichprobe für die Assoziation zugrunde. Gleiche Ergebnisse zeigen sich aber auch für den Transmission-Disequilibrium-Test an einer ASP-Stichprobe (Risch und Merikangas, 1996).

Die Grafik stellt die benötigten Stichprobengrößen für verschiedene relative genetische Risiken (GRR oder g) dar. Das GRR beschreibt die Erhöhung der Wahrscheinlichkeit des Auftretens des betrachteten Phänotyps für ein Individuum mit dem betrachteten Genotyp. Auf der $\mathrm{x}$-Achse sind verschiedene Allelfrequenzen des Risikoallels aufgetragen, die ebenfalls Auswirkung auf die statistische Aussagekraft haben.

Unter Annahme eines hohen GRR von $\geq 4$ und Allelfrequenzen von 0,05-0,5 liefern Kopplungs- und Assoziationsanalysen bereits für Stichprobengrößen unter 500 zuverlässige Ergebnisse.

Jedoch führt bereits eine mäßige Absenkung des GRR auf $\leq 2$ dazu, dass in der Kopplungsanalyse unrealistisch große Stichproben von mehreren Tausend Proben untersucht werden müssten, um die Kopplung am betrachteten Locus zu detektieren.

Ein Vorteil von SNP-Markern ist die kostengünstigere und schnellere Typisierung. Außerdem sind SNPs häufiger und gleichmäßiger im Genom verteilt, eine 
Eigenschaft, die vor allem für die Feinkartierung von Nutzen ist (Chen et al., 2007; Dekkers und Rothschild, 2007; Du et al., 2007).

Ferner können SNPs im Gegensatz zu Mikrosatelliten auch in Exons und/oder regulatorischen Elementen in Promoterregionen lokalisiert sein. Damit besteht die Möglichkeit, potentiell kausale Mutationen direkt auf ihre Assoziation zum Phänotyp zu überprüfen.

\subsubsection{Funktionelle Kandidatengene - Back to the future?}

Obwohl die Assoziationsanalyse eine größere statistische Aussagekraft hat und damit die zu untersuchenden Tierzahlen eingeschränkt werden können, müssen SNPMarker zur Detektion eines LD sehr dicht positioniert sein. Du und Kollegen berechneten die Ausdehnung des LD im Genom des Schweins anhand der Typisierung von 4.500 SNP-Markern in 6.000 Tieren aus sechs kommerziellen Schweinerassen und schlagen anhand ihrer Ergebnisse einen Markerabstand von 0,3 cM für genomweite LDScans vor (Du et al., 2007).

Die im initialen Genomscan als zu den Hernia $i / s$ gekoppelt nachgewiesenen Genomregionen umfassen insgesamt etwa $114 \mathrm{cM}$. Demnach wären für eine Feinkartierung per Assoziationsanalyse noch 380 Marker notwendig. Durch die Bestimmung funktioneller Kandidatengene innerhalb der gekoppelten Regionen könnte die Typisierung auf SNP-Marker in Kandidatengenen beschränkt werden.

Für den Defekt Hernia $i / s$ gestaltet sich allerdings die Identifikation funktioneller Kandidatengene aus folgenden Gründen besonders schwierig:

a) Mausmodelle für den Verschluss des PV sind aufgrund der unterschiedlichen physiologischen Gegebenheiten (nicht obliterierender PV bei Nagetieren) nicht verfügbar.

b) Es existieren widersprüchliche Hypothesen/Ergebnisse zur Ätiologie (Ausbildung von Muskelzellen am PV und Gubernaculum testis und Apoptose versus CGRP-induzierte Epithelfusion).

c) Die phänotypische Diagnose erfolgt erst nachdem sich die eigentliche Prädisposition bereits manifestiert hat.

Aus diesen Gründen waren die Versuche, genetische Ursachen der Hernia i/s auf Basis rein funktioneller Kandidatengenanalysen $\mathrm{zu}$ entdecken, nicht von Erfolg gekrönt. 
Die Analyse der Kalziumgehalte im Processus vaginalis und dem Peritoneum von Schweinen mit Hernia i/s sollen deshalb der Aufklärung der Ätiologie des Defekts dienen (Beuermann et al., 2007).

Des Weiteren könnten RNA-Analysen zu verschiedenen Zeitpunkten vor und nach erfolgtem DT unternommen werden, um zunächst diejenigen Gene zu identifizieren, die während der Obliteration des PV exprimiert werden. Ein großes Problem für die genaue Untersuchung der Ätiologie der Hernia i/s stellt die Tatsache dar, dass die Prädisposition, die zur Ausprägung des Defekts führt, zum Zeitpunkt der Diagnosestellung bereits stattgefunden hat. Umgekehrt müssten Tiere zu Untersuchungszwecken getötet werden, bevor eine eindeutige Diagnose gestellt werden kann. An Klonen eines oder mehrerer Tiere, die den Phänotyp Hernia i/s zeigen, könnten differentielle Expressionsuntersuchungen zum Zeitpunkt der Obliteration des PV durchgeführt werden. Weil der zu erwartende Phänotyp bereits am Donortier beobachtet wurde, ist eine Diagnosestellung für die Klone nicht mehr nötig.

Die Gruppe der funktionellen Kandidatengene könnte somit durch nichtdifferentielle und auch differentielle Expressionsanalysen genauer definiert werden. Unter Verwendung komparativer Genomkarten könnten funktionelle Kandidatengene dann den defektgekoppelten Chromosomenregionen zugeordnet werden.

Bereits bekannte starke funktionelle Kandidatengene wie zum Beispiel das $C G R P$ und der $A R$ sollten aber, obwohl sie außerhalb der von Bornemann-Kolatzki (2004) beschriebenen gekoppelten Genomregionen lokalisiert sind, trotzdem auf ihre mögliche Assoziation mit dem Merkmal untersucht werden, da in der Analyse von Grindflek und Kollegen eine Kopplung für die Region der beiden Gene gefunden wurde (Grindflek et al., 2006) und ein Effekt der Gene deshalb und insbesondere im Licht der oben diskutierten Limitationen der Kopplungsanalyse noch nicht eindeutig ausgeschlossen werden kann (vergleiche dazu auch Rothschild et al., 2007).

Für funktionell-positionelle Kandidatengene, lassen sich SNPs mit den jüngst entwickelten Hochdurchsatz-Sequenzierungsmethoden einfach und kostengünstig detektieren. Albert und Kollegen beschreiben die direkte Genomische Selektion und anschließende Sequenzierung von insgesamt 6.726 verschiedenen exonischen Sequenzen mit einer mittleren Länge von 500 bp. Die genomischen Sequenzen wurden durch Microarray-Hybridisierung selektiert und damit im Vergleich zum Gesamtgenom 
600-fach angereichert, durch die anschließende Sequenzierung mittels eines 454 Life Sciences FLX Sequencers konnte eine durchschnittliche 7-fache Abdeckung pro Einzelbase erzielt werden (Albert et al., 2007). Diese und ähnliche Techniken erlauben die hochparallele Detektion von Polymorphismen in verschiedenen Kandidatengenen und bieten sich deshalb insbesondere für die Genomanalyse der komplex vererbten Erkrankungen an. 


\section{Der 37-kDa/67-kDa Lamininrezeptor (Precursor) im Interspeziesvergleich}

\subsection{Transmissible Spongiforme Enzephalopathien}

Prion-Erkrankungen oder Transmissible Spongiforme Enzephalopathien (TSE) sind neurodegenerative Erkrankungen, die klinisch durch Demenz (beim Menschen) und Bewegungsstörungen auffallen. Im Gehirn zeigen sich typische pathologische Veränderungen, die zur eindeutigen Diagnose einer Prion-Erkrankung herangezogen werden. Diese typischen Veränderungen sind: Vakuolen im Neuropil des zerebralen beziehungsweise zerebellären Kortex oder der subkortikalen grauen Substanz, Neuronenverlust und astrozytäre Gliose (Budka et al., 1995). TSE können als einzige bekannte Erkrankungsgruppe sporadisch oder erblich auftreten und sind zudem übertragbar. $\mathrm{Zu}$ den humanen TSE gehört neben der Kuru die Creutzfeldt-JakobKrankheit (CJD) mit den Subfromen sporadisch, iatrogen, variant sowie familiär/hereditär. $\mathrm{Zu}$ den hereditär bedingten humanen TSE gehören auch das Gerstmann-Sträussler-Scheinker-Syndrom und die Fatale Familiäre Insomnie (Übersicht in Prusiner, 2004). Bei Tieren sind die Traberkrankheit bei Schafen (Scrapie) (McGowan, 1922) sowie die Bovine Spongiforme Enzephalopathie (BSE) (Wells et al., 1987), die Chronic Wasting Disease (CWD) der Hirsche (Williams und Young, 1980), die Transmissible Mink Encephalopathy (TME) der Nerze (Hartsough und Burger, 1965) und die Feline Transmissible Enzephalopathie (FSE) bei Haus- und Wildkatzen (Pearson et al., 1992) beschrieben.

Das Prion wird als das infektiöse Agens der TSE angesehen. Es wurde 1982 von Stanley B. Prusiner als solches beschrieben und mit dem $\operatorname{PrP}^{\mathrm{Sc}}$ (scrapie-associated prion protein) gleichgesetzt (Prusiner, 1982). Der Protein-only-Hypothese entsprechend ist das infektiöse Agens der TSE weitgehend frei von Nukleinsäuren und stellt eine abnorm gefaltete Form des zellulären Prionproteins $\left(\mathrm{PrP}^{\mathrm{c}}\right.$, cellular prion protein) dar. $\operatorname{PrP}^{\mathrm{c}}$ wird durch das wirtseigene Prion-Gen (PRNP) kodiert.

Allerdings liefern Untersuchungen anderer Autoren Hinweise darauf, dass TSE mit dem Auftreten von virusähnlichen Partikeln assoziiert sein könnten (Manuelidis et 
$a l .$, 2007). Außerdem ist die Abwesenheit einer wirtsunabhängigen Nukleinsäure mit Beteiligung an der Übertragung der TSE bis heute noch nicht eindeutig bewiesen (Somerville, 2002). Sicherlich sind aber das wirtseigene $\operatorname{PrP}^{c}$ und seine Umfaltung zu $\mathrm{PrP}^{\mathrm{Sc}}$ am Verlauf und an der Übertragung der Erkrankung zumindest entscheidend beteiligt.

Mit Hilfe der Kernspinresonanzspektroskopie (NMR, nuclear magnetic resonance spectroscopy) wurde zunächst die Proteinstruktur des murinen $\operatorname{PrP}^{\mathrm{c}}$ aufgeklärt (Riek et al., 1996). Darauf folgende NMR-Untersuchungen von $\operatorname{PrP}^{c}$ aus verschiedenen Spezies zeigten, dass das $\operatorname{PrP}^{c}$ zwischen den betrachteten Spezies hoch konserviert ist und dieselbe globale Architektur aufweist. $\operatorname{PrP}^{\mathrm{c}}$ besteht aus einem 100 Aminosäuren umfassenden unstrukturierten N-terminalen Bereich und einer Cterminalen globulären Domäne, die aus drei $\alpha$-Helices und einem kurzen antiparallelen B-Faltblatt besteht (Lysek et al., 2005).

In Infrarot-spektroskopischen-Untersuchungen wurde für $\mathrm{PrP}^{c}$ ein $42 \%$ iger Gehalt an $\alpha$-Helices und ein 3\%iger Gehalt an B-Faltblatt-Strukturen nachgewiesen. $\mathrm{PrP}^{\mathrm{Sc}}$ dagegen enthält nur 30\% $\alpha$-Helices, aber $43 \%$ B-Faltblätter (Cohen et al., 1994). Durch die abnorme Faltung zeigt $\operatorname{PrP}^{\mathrm{Sc}}$ eine partielle Resistenz gegenüber Proteinase-KAbbau und ist in Detergenzien schwerer in Lösung zu bringen (Prusiner, 1982; McKinley et al., 1983; Oesch et al., 1985).

Der exakte Mechanismus der Umfaltung von $\operatorname{PrP}^{\mathrm{c}} \mathrm{zu} \operatorname{PrP}^{\mathrm{Sc}}$ konnte bis heute noch nicht aufgeklärt werden, in der Literatur wurden dazu verschiedene Modelle vorgestellt. Das katalytische Modell beschreibt die template-assisted prion formation, in der $\operatorname{PrP}^{\mathrm{Sc}}$ als Katalysator die Umfaltung des wirtseigenen $\operatorname{PrP}^{\mathrm{c}}$ bewirkt und dem neu entstehenden $\operatorname{PrP}^{\mathrm{Sc}}$ dabei seine eigene Prägung verleiht. Die jeweilige Prägung des Donor-PrP $\mathrm{P}^{\mathrm{Sc}}$ liegt, dem katalytischen Modell zufolge, in der Tertiärstruktur des Proteins begründet und bedingt die verschiedenen Eigenschaften der verschiedenen prion strains (Prusiner, 1991; Prusiner, 2004).

Das katalytische Modell wurde später um die mögliche Mitwirkung eines zweiten oder mehrerer anderer Proteine erweitert. Bei dem zunächst als „Protein X“ bezeichneten Faktor könnte es sich zum Beispiel um ein Chaperon handeln (Prusiner, 2004). 
Als weiteres alternatives Modell wurde der nucleated-polymerizationmechanism vorgeschlagen, dem zufolge aggregierte $\operatorname{Pr}^{\mathrm{Sc}}$-Moleküle die Umfaltung von $\operatorname{PrP}^{c}$ effizienter katalysieren als einzelne $\mathrm{PrP}^{\mathrm{Sc}}$-Moleküle (Caughey et al., 1995).

Die meisten zellulären PrP befinden sich an der Außenseite der Zellmembran, wo sie durch einen GPI-Rest (GPI = Glycosylphosphatidylinositol) verankert sind (Stahl et al., 1987).

$\mathrm{PrP}^{c}$ unterliegt, wie die meisten Proteine, einem ständigen turn-over. Bisher wurden kontroverse Ergebnisse zum Mechanismus der Internalisierung des membranassoziierten $\operatorname{PrP}^{\mathrm{c}}$ veröffentlicht. Vey und Kollegen beschreiben eine Lokalisation/Internalisierung von $\mathrm{PrP}^{\mathrm{c}} /^{\mathrm{Sc}}$ in caveolae-like domains (CLDs, auch: lipid rafts) (Vey et al., 1996), während Shyng und Kollegen die Lokalisation von $\operatorname{PrP}^{c}$ in clathrin-coated pits/vesicles nachweisen konnten (Shyng et al., 1994). Inzwischen geht man davon aus, dass im Lebenszyklus des $\operatorname{PrP}^{c}$ beide Internalisierungswege vorkommen (Harris et al., 2004). Morris und Kollegen gehen davon aus, dass $\operatorname{PrP}^{c}$ an der Zellmembran von seiner ursprünglichen Lokalisation in den CLDs zu den clathrincoated pits wandert, um dort internalisiert zu werden (Morris et al., 2006).

Ferner wird die Endozytose eines Liganden in clathrin-coated vesicles durch Transmembranrezeptoren vermittelt, die über ein spezifisches, zytoplasmatisches Aminosäurenmotiv verfügen, durch das sie nach Aktivierung - i.d.R. nach erfolgter Ligandenbindung - in den clathrin-coated pits festgehalten und anschließend internalisiert werden. Als GPI-verankertes Protein verfügt $\operatorname{PrP}^{\mathrm{c}}$ nicht über eine solche zytoplasmatische Domäne und somit muss seine Internalisierung in die clathrin-coated vesicles über einen Rezeptor vermittelt werden (Harris et al., 2004; Morris et al., 2006).

1999 wurde dem 37-kDa Lamininrezeptor Precursor (LRP) diese Funktion zugeschrieben (Rieger et al., 1999), nachdem LRP in Hefe-Dihybrid-Experimenten als Bindungspartner für $\operatorname{PrP}^{c}$ identifiziert werden konnte (Rieger et al., 1997).

Jüngst beschrieben Taylor und Hooper, einen weiteren $\mathrm{Cu}^{2+}$-abhängigen Internalisierungsweg für $\mathrm{PrP}^{\mathrm{c}}$, der durch das $L D L$ receptor-related protein 1 vermittelt wird (Taylor und Hooper, 2007).

\subsection{Der 67-kDa/37-kDa Lamininrezeptor (Precursor)}

Der gereifte Lamininrezeptor (LR) hat ein Molekulargewicht von 67-kDa und entsteht durch einen bis heute noch nicht vollständig aufgeklärten Mechanismus aus 
dem 37-kDa LRP. Eine Theorie beschreibt eine Homodimerisierung zweier LRP zur 67-kDa Form des LRs (Landowski et al., 1995). Neuere Untersuchungen gehen allerdings davon aus, dass es sich beim LR um ein Heterodimer aus LRP und einem weiteren noch unbekanntem Protein handelt (Castronovo et al., 1991; Buto et al., 1998). Daten aus einem Hefe-Dihybrid-Experiment, in dem die Homodimerisierung des LRPs nicht festgestellt werden konnte, stützen die Heterodimerhypothese (Hundt et al., 2001).

Die humane mRNA des LRP/LR-Gens kodiert den aus 295 Aminosäuren bestehenden 37-kDa Precursor (Yow et al., 1988). Für das LRP/LR-Gen (nach offizieller HGNC-Nomenklatur als RPSA, ribosomal protein A, bezeichnet) existiert in den Genomen der bisher untersuchten Säugetiere eine große Zahl von Pseudogenen, zu Projektbeginn waren sechs murine und 26 humane $L R P / L R$-Pseudogene beschrieben (Jackers et al., 1996).

Die Existenz der Pseudogene erschwert die Klonierung des funktionellen Gens. Aus diesem Grund lagen zu Projektbeginn lediglich die vollständigen, genomischen Sequenzen des Menschen (Jackers et al., 1996b) und des Huhns (Clausse et al., 1996) vor. Für das Rind (Grosso et al., 1991) und die Maus (Rao et al., 1989; Grosso et al., 1991) lagen die Sequenzen aus cDNA-Klonen in den Datenbanken vor. Zudem stellte sich heraus, dass die Aminosäurensequenzen der orthologen LRP/LR hoch konserviert sind (Grosso et al., 1991).

Beim LRP/LR handelt es sich um ein multifunktionelles Protein, das sowohl mit der 40s ribosomal subunit im Zytoplasma assoziiert ist (Auth und Brawerman, 1992), als auch im Nukleus an die Histone H2A, H2B und H4 gebunden ist (Ardini et al., 1998; Kinoshita et al., 1998). An der Zelloberfläche wirken LRP/LR als Rezeptoren für Laminin, Elastin und Kohlenhydrate (Ardini et al., 1998). Außerdem bilden LRP/LR die Eintrittspforte für verschiedene Viren, namentlich für das Sindbis Virus (Wang et al., 1992), das Venezuelanische Equine Enzephalitis Virus (Ludwig et al., 1996), das Adeno-assoziierte Virus (Akache et al., 2006) und das Dengue Virus (Tio et al., 2005).

Gauczynski und Kollegen konnten zeigen, dass sowohl LRP als auch LR an der Zelloberfläche von neuronalen sowie von nichtneuronalen BHK-Zellen (BHK = baby hamster kidney) mit $\operatorname{PrP}^{\mathrm{c}}$ kolokalisiert sind. Außerdem konnten die Autoren an BHKZellen, die eine nichtfunktionsfähige Deletionsvariante des LRPs/LRs exprimierten, zeigen, dass ohne den funktionsfähigen LRP/LR keine Internalisierung des $\operatorname{PrP}^{\mathrm{c}}$ stattfindet (Gauczynski et al., 2001). 
Weiterführende Studien derselben Arbeitsgruppe ergaben (Abbildung 3-1), dass LRP/LR nicht nur für die Aufnahme von $\mathrm{PrP}^{\mathrm{c}}$ sondern auch von $\operatorname{PrP}^{\mathrm{Sc}}$ notwendig ist (Leucht et al., 2003).

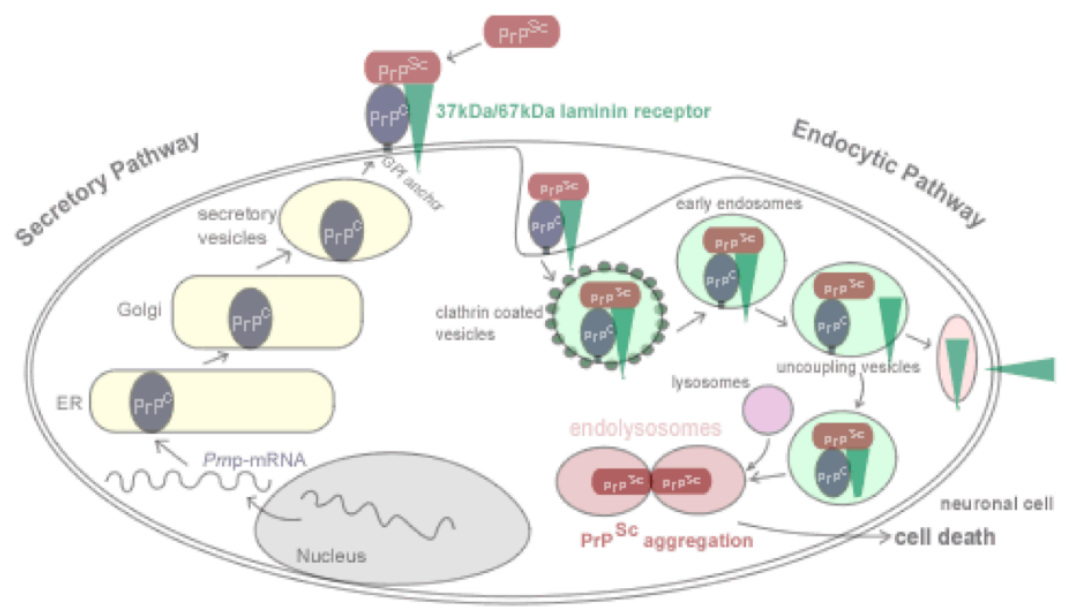

\begin{abstract}
Abbildung 3-1: Lebenszyklus von Prionen (Abbildung übernommen aus Weiss, 2005). Das zelluläre Prionprotein durchläuft den sekretorischen pathway und gelangt an die Zelloberfläche, wo es GPI-verankert vorliegt. Die Internalisierung von $\operatorname{PrP}^{\mathrm{c}}$ erfolgt LRP/LR-abhängig, vermutlich in clathrin-coated vesicles. $\mathrm{PrP}^{\mathrm{c}}$ und LRP/LR gelangen zum Teil zurück an die Zelloberfläche (,Recycling“) oder werden in späten Kompartimenten des endozytotischen Weges (Lysosomen, Endolysosomen) abgebaut. $\operatorname{PrP}^{\text {Sc }}$ gelangt vermutlich LRP/LR- und $\operatorname{PrP}^{\mathrm{c}}$ vermittelt in die Zelle. Wird LRP/LR durch Antikörper blockiert oder seine Expression z.B. durch siRNAs gehemmt, kann $\operatorname{PrP}^{\mathrm{c} / \mathrm{Sc}}$ nicht mehr internalisiert werden (Leucht et al., 2003). Die $\mathrm{PrP}^{\mathrm{Sc}}$-Propagation kommt zum Erliegen. Die als Korezeptoren fungierenden Heparansulfatproteoglukane sind in dieser Abbildung nicht dargestellt.
\end{abstract}

Des Weiteren wurden am LRP/LR zwei voneinander unabhängige Bindungsstellen für $\operatorname{PrP}^{c / S c}$ identifiziert. Eine Bindungsstelle des Rezeptors (zwischen Aminosäuren 157 und 180) tritt in direkte Interaktion mit $\operatorname{PrP}^{c}$. Sie entspricht der für Laminin beschriebenen Bindungsstelle. Neben der direkten Bindungsdomäne konnte eine weitere indirekte Bindungsstelle für $\operatorname{PrP}^{\mathrm{c} / \mathrm{sc}}$ am $\mathrm{LRP} / \mathrm{LR}$ ermittelt werden. Die Bindung an dieser Domäne wird durch Heparansulfatproteoglukane (HSPGs) vermittelt. Die HSPG-abhängige Bindung erfolgt entweder im Bereich der Aminosäuren 180 bis 295 oder 101 bis 160 des LRP (Hundt et al., 2001). Diese Ergebnisse sind kongruent zu Veröffentlichungen anderer Arbeitsgruppen, die ebenfalls Heparansulfat als Bindungspartner für $\mathrm{PrP}^{\mathrm{Sc}}$ benennen (Horonchik et al., 2005). Abbildung 3-2 stellt das Modell der HSPG- und LRP/LR-abhängigen Internalisierung von $\operatorname{PrP}^{\mathrm{c}}$ und $\operatorname{PrP}^{\mathrm{Sc}}$ dar. 
Aus der inhibierenden Wirkung der heparan mimetics für die Aufnahme von $\mathrm{PrP}^{\mathrm{Sc}}$ in die Zelle leiten verschiedene Autoren einen möglichen therapeutischen Einsatz dieser Substanzen ab (Adjou et al., 2003; Gauczynski et al., 2006).

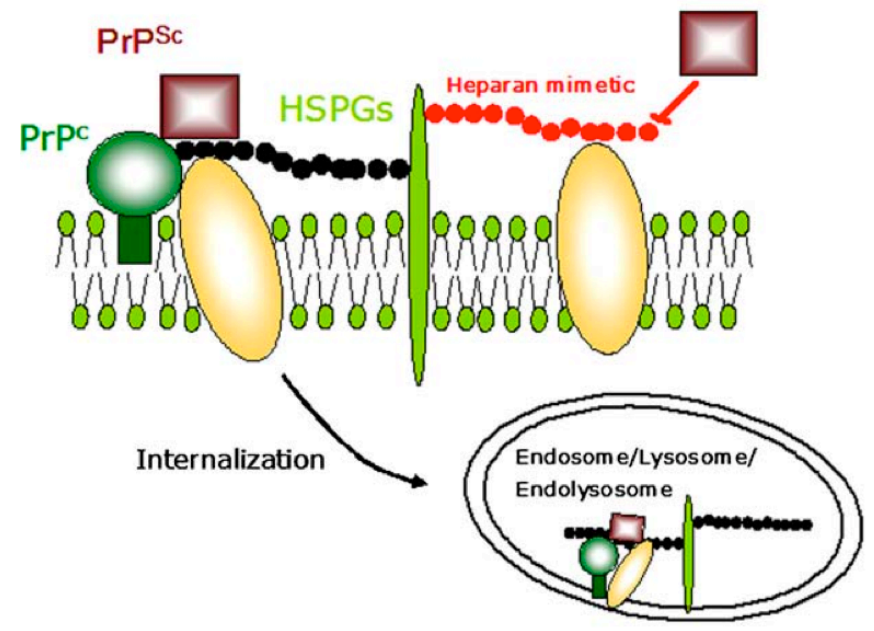

Abbildung 3-2: Modell der HSPG-vermittelten Aufnahme von $\operatorname{PrP}^{\mathrm{c}}$ und $\mathrm{PrP}^{\mathrm{Sc}}$ (Abbildung verändert nach Vana et al., 2007). Das GPI-verankerte $\operatorname{PrP}^{\mathrm{c}}$ bindet über eine direkte und eine HSPG-abhängige Bindungsstelle an LRP/LR. PrP ${ }^{\mathrm{Sc}}$ bindet durch die Vermittlung von $\operatorname{PrP}^{\mathrm{c}}$ und der Heparansulfat-Seitenkette des HSPG. Der PrP/HSPG/LRP/LR-Komplex wird dann in Endo- bzw. Lysosomen internalisiert. Heparan mimetics wie HM2602 und HM5004 reduzieren die Bindung von $\mathrm{PrP}^{\mathrm{Sc}}$ an den Rezeptorkomplex (Gauczynski et al., 2006).

\subsection{Die Speziesbarriere}

Die Interspeziesübertragung des $\mathrm{PrP}^{\mathrm{Sc}}$ vom Schaf auf das Rind erfolgte durch kontaminierte Futtermittel in Großbritannien (Wilesmith et al., 1988). Außerdem gilt es als gesichert, dass der BSE-Erreger vom Rind auf den Menschen und auf die Katze ebenfalls mit der Nahrung übertragen wurde (Bruce et al., 1994; Collinge et al., 1996). Das Auftreten einer neuen Variante der CJD (vCJD) in Großbritannien und in Frankreich ist wahrscheinlich auf eine Infektion mit dem BSE-Erreger über die Nahrungskette zurückzuführen (Hill et al., 1997). Die orale Übertragbarkeit von $\mathrm{PrP}^{\mathrm{Sc}}$ sowohl innerhalb einer Spezies als auch zwischen verschiedenen Spezies gilt als bewiesen.

Allerdings zeigen Übertragungsversuche, die vor allem mit transgenen Mäusen durchgeführt wurden, dass eine Übertragung der Erkrankung weniger effizient erfolgt, wenn Tiere, die $\operatorname{PrP}^{c}$ einer bestimmten Spezies exprimieren, mit $\operatorname{PrP}^{\mathrm{Sc}}$ einer anderen Spezies infiziert werden. Dies äußert sich entweder in einer verlängerten Inkubationszeit, einer verminderten Infektionsrate oder einer generellen Resistenz der 
experimentell infizierten Mäuse (Scott et al., 2004; Scott et al., 2005). In der Literatur wird die ineffizientere Übertragung der TSE zwischen verschiedenen Spezies im Allgemeinen mit dem Begriff Speziesbarriere (species barrier) beschrieben (Scott et al., 2004).

Verschiedene Tierarten, namentlich Schweine, Hühner, Kaninchen und Hunde, zeigen eine generelle Resistenz gegenüber oraler Infektion mit dem Erreger der TSE (Matthews und Cooke, 2003; Vorberg et al., 2003; Lysek et al., 2005). Mäuse entwickeln auch nach intrakranieller Injektion mit Erregern der Transmissiblen Enzephalopathie der Nerze keine TSE (Scott et al., 2004). In diesem Fall liegt eine absolute Speziesbarriere vor, wohingegen Schweine bei parenteraler Verabreichung von BSE-Prionen durchaus Krankheitssymptome entwickeln können und deshalb zwar eine hohe, aber keine absolute, Barriere für die Übertragung von $\operatorname{PrP}^{\mathrm{Sc}}$ zwischen Rind und Schwein angenommen werden kann (Wells et al., 2003).

Für die Empfänglichkeit/Resistenz gegenüber $\operatorname{PrP}^{\mathrm{Sc}}$ spielt die Aminosäurensequenz sowohl des Donor- $\operatorname{PrP}^{\mathrm{Sc}}$ als auch des Akzeptor- $\mathrm{PrP}^{\mathrm{c}}$ eine entscheidende Rolle. Zum einen kann die Aminosäurensequenz des Akzeptors die Umfaltung von $\operatorname{PrP}^{\mathrm{c}} \mathrm{zu} \mathrm{PrP}^{\mathrm{Sc}}$ erschweren oder ganz verhindern. Hier sind beispielsweise die resistenten Haplotypen des $P R N P$ bei Schafen $\left(\mathrm{A}^{136} \mathrm{R}^{154} \mathrm{R}^{171}\right.$ und $\left.\mathrm{A}^{136} \mathrm{H}^{154} \mathrm{Q}^{171}\right) \mathrm{zu}$ nennen (Goldmann et al., 2005). Zum anderen wird von verschiedenen Autoren postuliert, dass neben der notwendigen Ähnlichkeit der Primärstrukturen von PrP ${ }^{\mathrm{c}}$ Akzeptor und $\mathrm{PrP}^{\mathrm{Sc}}$-Donor die strain-spezifische Tertiärstruktur des infizierenden $\operatorname{PrP}^{\mathrm{Sc}}$ den größten Einfluss auf die Effizienz der Übertragung der TSE zwischen verschiedenen Spezies ausübt (Vorberg et al., 2003; Castilla et al., 2004; Scott et al., 2004; Scott et al., 2005).

Dennoch bleibt zu vermuten, dass die beschriebenen Einflüsse der Primär- und der Tertiärstruktur von $\operatorname{PrP}^{\mathrm{c} / \mathrm{sc}}$ nicht die einzigen Determinanten der Speziesbarriere darstellen. So zeigen QTL-Studien an Mäusen und Schafen, dass neben dem PRNP-Gen selbst noch eine Reihe weiterer, noch nicht näher charakterisierter Gene auf die Variabilität der Inkubationszeiten innerhalb derselben Spezies Einfluss nehmen (Lloyd et al., 2001; Manolakou et al., 2001; Lloyd et al., 2002; Moreno et al., 2003b; Moreno et al., 2003a). 
Aus der Studie von Wells und Kollegen (2003) ergaben sich zu Beginn der hier vorgestellten Arbeiten erste Hinweise auf eine verminderte Aufnahme des infektiösen Agens im Darm von Schweinen.

Beim Menschen konnten zwei verschiedene Expressionsmuster des LRP/LR an der intestinalen Mukosa festgestellt werden. Shmakov und Kollegen beschreiben die Expression des LRP/LR auf der apikalen Epithelmembran in etwa $40 \%$ der untersuchten Dünndarm-Biopsien. In den verbleibenden 60\% der Gewebeproben zeigte sich im Gegensatz dazu eine Expression an den Endothelzellen. Die Autoren folgern aus ihren Ergebnissen, dass die Lokalisation des LRP/LR an der apikalen Membran der Epithelzellen ein höheres Risiko für eine orale $\mathrm{PrP}^{\mathrm{Sc}}$-Infektion bedingt, da der LRP/LR in diesem Fall direkten Kontakt zum oral aufgenommenen Erreger hat (Shmakov et al., 2000).

Überdies konnte in einem Zellkulturmodell des humanen Dünndarmepithels (Caco-2-Zellen, Caco = carcinoma colon $)$ nachgewiesen werden, dass die Aufnahme von PrPSc aus BSE-Hirnhomogenaten in Abhängigkeit von LRP/LR erfolgt. Im Gegensatz dazu wurde mausadaptiertes PrPSc aus Scrapie-Hirnhomogenaten nicht aufgenommen (Morel et al., 2005). Aus diesen Ergebnissen ergibt sich ein weiterer klarer Hinweis auf eine Beteiligung der rezeptorvermittelten Aufnahme von PrPSc an der Speziesbarriere.

\subsection{Darstellung des Forschungsprojektes}

Das in der vorliegenden Arbeit vorgestellte Projekt umfasste in der ursprünglichen Planung die Charakterisierung der bovinen und porcinen Gene für LRP/LR. Dabei war die Arbeitshypothese, dass funktionelle und strukturelle Varianten in den LRP/LR-Genen zwischen TSE-empfänglichen und TSE-unempfänglichen Spezies bestehen. Durch Vergleich LRP-kodierender DNA-Sequenzen sollten mögliche Unterschiede aufgedeckt werden, die eine Bindung und Internalisierung von $\operatorname{PrP}^{\mathrm{Sc}}$ durch den porcinen LRP/LR verhindern. Die Ergebnisse dieser Untersuchungen wurden in zwei Publikationen (Germerodt et al., 2004; Knorr et al., 2007) veröffentlicht. 


\subsection{Diskussion und Ausblick}

Die Effizienz der Übertragung des TSE-Erregers zwischen verschiedenen Spezies hängt in starkem Maße vom Grad der Homologie zwischen PrP ${ }^{c}$-Akzeptor und $\mathrm{PrP}^{\mathrm{Sc}}$-Donor ab (Vorberg et al., 2003). Nichtsdestotrotz kann die Beteiligung anderer Proteine/Faktoren an der Speziesbarriere nicht ausgeschlossen werden. Deshalb wurden die Aminosäurensequenzen des LRP/LR von Rind, Schwein, Maus, Huhn und Mensch miteinander verglichen. Diese grundlegenden Vergleiche sollten zeigen, ob sich auf Ebene der Primärstruktur des Proteins Unterschiede zwischen den Spezies, die unterschiedlich empfänglich für TSE sind, nachweisen lassen.

Es stellte sich heraus, dass es sich bei LRP/LR um ein hochkonserviertes Protein handelt. Innerhalb der direkten PrP-Bindungsdomäne fanden sich keine Unterschiede in der Aminosäurensequenz der verschiedenen Spezies.

Während an der direkten Bindungsdomäne jedoch vor allem $\operatorname{PrP}^{\mathrm{c}}$ bindet, ist die indirekte Bindungsdomäne vor allem für die Bindung und Internalisierung von $\operatorname{PrP}^{\mathrm{Sc}}$ von entscheidender Bedeutung (Hundt et al., 2001; Gauczynski et al., 2006).

Innerhalb der indirekten Bindungsdomäne bestehen zwischen Rind und Schwein nur an zwei Positionen (A/T an Position 241 und $\mathrm{S} / \mathrm{T}$ an Position 272) Aminosäurenunterschiede. Computergestützte Prognosen zu den Sekundär- und Tertiärstrukturen der Proteine ließen jedoch keine gravierenden strukturellen Unterschiede zwischen dem porcinen und dem bovinen Rezeptor vermuten. Aufgrund der gefundenen Polymorphismen im Bereich der HSPG-abhängigen Bindungsdomäne lässt sich jedoch nicht ausschließen, dass der porcine LRP/LR eine schwächere Bindungsaffinität gegenüber $\operatorname{PrP}^{\mathrm{Sc}}$ aufweist als der bovine Rezeptor.

Weitere Experimente zur Ermittlung der Bindungsaffinitäten verschiedener LRP/LR zu verschiedenen Donor-PrP ${ }^{\mathrm{Sc}}$-Molekülen werden aufdecken, ob die Aminosäurenunterschiede Auswirkungen auf die Bindung des procinen Rezeptors an den Liganden $\operatorname{PrP}^{\mathrm{c} / \mathrm{sc}}$ haben. Eine Reihe an experimentellen Methoden zur Detektion und Charakterisierung von Protein-Protein-Interaktionen sind von Phizicky und Fields (1990) beschrieben.

Weitere Untersuchungen zur Ermittlung der Tertiärstruktur zum Beispiel mit den Methoden der NMR (Wüthrich, 1990) oder der Röntgenkristallographie können 
weiteren Aufschluss über eventuell bestehende Unterschiede in der Architektur der LRP/LR verschiedener Spezies liefern.

Im Vergleich zu TSE-empfänglichen Spezies unterschiedliche Expressionsmuster des Rezeptors im Dünndarm des Schweins, die durch Unterschiede in der Promoterregion des Gens bedingt sind, können ebenfalls eine verminderte Aufnahme des Erregers bedingen.

Die ursprünglich angestrebte Sequenzierung der RPSA des Rinds und des Schweins konnte bisher nicht abgeschlossen werden. Die Isolierung von Klonen aus entsprechenden Genbanken wurde durch die große Anzahl von RPSA-Pseudogenen in beiden Genomen maßgeblich erschwert. Mit der voranschreitenden Sequenzierung des porcinen und bovinen Genoms werden aber in naher Zukunft die funktionellen RPSA in silico $\mathrm{zu}$ isolieren sein. Nach Ermittlung des Transkriptionsstarts kann die Promoterregion des Gens vergleichend untersucht werden. Unterschiede, die Bindungsstellen für Transkriptionsfaktoren betreffen, können Hinweise auf Differenzen in der Expression zwischen den Spezies liefern.

Direkte Hinweise auf eine differentielle Expression des Rezeptors im Dünndarm von unterschiedlich empfänglichen Spezies könnten histologische Färbungen oder Bindungsexperimente an Organkulturen liefern. 


\section{Literaturverzeichnis}

Adham, I.M., Burkhardt, E., Benahmed, M. \& Engel, W. (1993): Cloning of a cDNA for a novel insulin-like peptide of the testicular Leydig cells. J Biol Chem 268:26668-26672.

Adjou, K.T., Simoneau, S., Sales, N., Lamoury, F., Dormont, D., Papy-Garcia, D., Barritault, D., Deslys, J.P. \& Lasmezas, C.I. (2003): A novel generation of heparan sulfate mimetics for the treatment of prion diseases. $J$ Gen Virol 84:2595-2603.

Akache, B., Grimm, D., Pandey, K., Yant, S.R., Xu, H. \& Kay, M.A. (2006): The 37/67-kilodalton laminin receptor is a receptor for adeno-associated virus serotypes 8, 2, 3, and 9. J Virol 80:9831-9836.

Albert, T.J., Molla, M.N., Muzny, D.M., Nazareth, L., Wheeler, D., Song, X., Richmond, T.A., Middle, C.M., Rodesch, M.J., Packard, C.J., Weinstock, G.M. \& Gibbs, R.A. (2007): Direct selection of human genomic loci by microarray hybridization. Nat Methods 4:903-905.

Althoff, W. (1985): Zur erblichen Abhängigkeit verschiedener Geburtsfehler beim Schwein. Dissertation, Universität Bonn.

Althoff, W., Mayer, M., Richter, L. \& Simon, D. (1988): Zur erblichen Abhängigkeit der Geburtsfehler Brüche und Binnenhodigkeit beim Schwein. Züchtungskunde 60:319-329.

Amann, R.P. \& Veeramachaneni, D.N. (2007): Cryptorchidism in common eutherian mammals. Reproduction 133:541-561.

Ardini, E., Pesole, G., Tagliabue, E., Magnifico, A., Castronovo, V., Sobel, M.E., Colnaghi, M.I. \& Menard, S. (1998): The 67-kDa laminin receptor originated from a ribosomal protein that acquired a dual function during evolution. Mol Biol Evol 15:1017-1025.

Auth, D. \& Brawerman, G. (1992): A 33-kDa polypeptide with homology to the laminin receptor: component of translation machinery. Proc Natl Acad Sci U S A 89:4368-4372.

Barthold, J.S. \& Redman, J.F. (1996): Association of epididymal anomalies with patent processus vaginalis in hernia, hydrocele and cryptorchidism. J Urol 156:20542056.

Beck, J., Knorr, C., Habermann, F., Fries, R. \& Brenig, B. (2002): Assignment of the beta-glucuronidase (GUSB) gene to porcine chromosome SSC3p16-->p14 by FISH and confirmation by hybrid panel analyses. Cytogenet Genome Res 97:277G.

Beck, J., Bornemann-Kolatzki, K., Knorr, C., Täubert, H. \& Brenig, B. (2006): Molecular characterization and exclusion of porcine GUSB as a candidate gene for congenital hernia inguinalis/scrotalis. BMC Vet Res 2:14.

Beißner, B. (2003): Genetische Analyse von angeborenen Anomalien bei den Nachkommen von Besamungsebern. Dissertation, Tierärztliche Hochschule Hannover.

Berge, S. (1941): The inheritance of paralysed hind legs, scrotal hernia and atresia ani in pigs. $J$ Hered 32:271-274.

Beuermann, C., Germerodt, M., Beck, J., Brenig, B. \& Knorr, C. (2008): Chromosomal assignment of eight porcine genes involved in apoptosis. Anim Genet 39. 
Beuermann, C., Beck, J., Schmelz, H., Dunkelberg, E., Schütz, E., Brenig, B. \& Knorr, C. (2007): Total calcium content differences in tissues of piglets with hernia inguinalis/scrotalis and cryptorchidism. J Animal Science eingereicht im Dezember 2007.

Bogatcheva, N.V., Truong, A., Feng, S., Engel, W., Adham, I.M. \& Agoulnik, A.I. (2003): GREAT/LGR8 is the only receptor for insulin-like 3 peptide. Mol Endocrinol 17:2639-2646.

Bornemann-Kolatzki, K. (2004): Durchführung eines Genomscans mit polymorphen DNA-Markern und Genomic Mismatch Scanning (GMS) bei Sus scrofa zur Detektion Hernia inguinalis/scrotalis assoziierter Genomregionen. Dissertation, Tierärztliche Hochschule Hannover \& Georg-August-Universität Göttingen.

Bruce, M., Chree, A., McConnell, I., Foster, J., Pearson, G. \& Fraser, H. (1994): Transmission of bovine spongiform encephalopathy and scrapie to mice: strain variation and the species barrier. Philos Trans $R$ Soc Lond B Biol Sci 343:405411.

Budka, H., Aguzzi, A., Brown, P., Brucher, J.M., Bugiani, O., Gullotta, F., Haltia, M., Hauw, J.J., Ironside, J.W., Jellinger, K. \& et al. (1995): Neuropathological diagnostic criteria for Creutzfeldt-Jakob disease (CJD) and other human spongiform encephalopathies (prion diseases). Brain Pathol 5:459-466.

Buto, S., Tagliabue, E., Ardini, E., Magnifico, A., Ghirelli, C., van den Brule, F., Castronovo, V., Colnaghi, M.I., Sobel, M.E. \& Menard, S. (1998): Formation of the $67-\mathrm{kDa}$ laminin receptor by acylation of the precursor. J Cell Biochem 69:244-251.

Castilla, J., Gutierrez-Adan, A., Brun, A., Doyle, D., Pintado, B., Ramirez, M.A., Salguero, F.J., Parra, B., Segundo, F.D., Sanchez-Vizcaino, J.M., Rogers, M. \& Torres, J.M. (2004): Subclinical bovine spongiform encephalopathy infection in transgenic mice expressing porcine prion protein. J Neurosci 24:5063-5069.

Castronovo, V., Claysmith, A.P., Barker, K.T., Cioce, V., Krutzsch, H.C. \& Sobel, M.E. (1991): Biosynthesis of the $67 \mathrm{kDa}$ high affinity laminin receptor. Biochem Biophys Res Commun 177:177-183.

Caughey, B., Kocisko, D.A., Raymond, G.J. \& Lansbury, P.T., Jr. (1995): Aggregates of scrapie-associated prion protein induce the cell-free conversion of proteasesensitive prion protein to the protease-resistant state. Chem Biol 2:807-817.

Chen, K., Baxter, T., Muir, W.M., Groenen, M.A. \& Schook, L.B. (2007): Genetic resources, genome mapping and evolutionary genomics of the pig (Sus scrofa). Int J Biol Sci 3:153-165.

Chen, K.F., Beck, J., Huang, L.S., Knorr, C. \& Brenig, B. (2004): Assignment of the phosphoglycerate kinase 2 (PGK2) gene to porcine chromosome 7q14-q15 by fluorescence in situ hybridization and by analysis of somatic cell and radiation hybrid panels. Anim Genet 35:71-72.

Ciobanu, D.C., Bastiaansen, J.W., Lonergan, S.M., Thomsen, H., Dekkers, J.C., Plastow, G.S. \& Rothschild, M.F. (2004): New alleles in calpastatin gene are associated with meat quality traits in pigs. J Anim Sci 82:2829-2839.

Clarnette, T.D. \& Hutson, J.M. (1999): The development and closure of the processus vaginalis. Hernia 3:97-102.

Clarnette, T.D., Lam, S.K. \& Hutson, J.M. (1998): Ventriculo-peritoneal shunts in children reveal the natural history of closure of the processus vaginalis. $J$ Pediatr Surg 33:413-416. 
Clausse, N., Jackers, P., Jares, P., Joris, B., Sobel, M.E. \& Castronovo, V. (1996): Identification of the active gene coding for the metastasis-associated 37LRP/p40 multifunctional protein. DNA Cell Biol 15:1009-1023.

Cohen, F.E., Pan, K.M., Huang, Z., Baldwin, M., Fletterick, R.J. \& Prusiner, S.B. (1994): Structural clues to prion replication. Science 264:530-531.

Collinge, J., Sidle, K.C., Meads, J., Ironside, J. \& Hill, A.F. (1996): Molecular analysis of prion strain variation and the aetiology of 'new variant' CJD. Nature 383:685690.

Collins, F.S. (1995): Positional cloning moves from perditional to traditional. Nat Genet 9:347-350.

Dahme, E. \& Weiss, E. (1999): Grundriß der speziellen pathologischen Anatomie der Haustiere. Verlag Enke, Stuttgart 1999.

Davey, R.B. (1997): Undescended testes: early versus late maldescent. Pediatr Surg Int 12:165-167.

Dekkers, J. \& Rothschild, M.F. (2007): New tools to make genetic progress. London Swine Conference - Today's Challenges... Tomorrow's Opportunisties, London, Proceedings of the London Swine Conference.

Ding, N. (2006): Deciphering the genetics of pig complex traits through QTL mapping and positional candidate cloning. Dissertation, Georg-August-Universität.

Donnell, S.C., Rickwood, A.M., Jee, L.D. \& Jackson, M. (1995): Congenital testicular maldescent: significance of the complete hernial sac. Br J Urol 75:702-703.

Du, F.X., Clutter, A.C. \& Lohuis, M.M. (2007): Characterizing linkage disequilibrium in pig populations. Int J Biol Sci 3:166-178.

El-Gehani, F., Zhang, F.P., Pakarinen, P., Rannikko, A. \& Huhtaniemi, I. (1998): Gonadotropin-independent regulation of steroidogenesis in the fetal rat testis. Biol Reprod 58:116-123.

Fentener van Vlissingen, J.M., van Zoelen, E.J., Ursem, P.J. \& Wensing, C.J. (1988): In vitro model of the first phase of testicular descent: identification of a low molecular weight factor from fetal testis involved in proliferation of gubernaculum testis cells and distinct from specified polypeptide growth factors and fetal gonadal hormones. Endocrinology 123:2868-2877.

Fentener van Vlissingen, J.M., Koch, C.A., Delpech, B. \& Wensing, C.J. (1989): Growth and differentiation of the gubernaculum testis during testicular descent in the pig: changes in the extracellular matrix, DNA content, and hyaluronidase, beta-glucuronidase, and beta- $\mathrm{N}$-acetylglucosaminidase activities. $J$ Urol 142:837-845.

Fujii, J., Otsu, K., Zorzato, F., de Leon, S., Khanna, V.K., Weiler, J.E., O'Brien, P.J. \& MacLennan, D.H. (1991): Identification of a mutation in porcine ryanodine receptor associated with malignant hyperthermia. Science 253:448-451.

Gatphayak, K., Knorr, C., Beck, J. \& Brenig, B. (2004): Molecular characterization of porcine hyaluronidase genes 1,2 , and 3 clustered on SSC13q21. Cytogenet Genome Res 106:98-106.

Gauczynski, S., Nikles, D., El-Gogo, S., Papy-Garcia, D., Rey, C., Alban, S., Barritault, D., Lasmezas, C.I. \& Weiss, S. (2006): The 37-kDa/67-kDa laminin receptor acts as a receptor for infectious prions and is inhibited by polysulfated glycanes. J Infect Dis 194:702-709.

Gauczynski, S., Peyrin, J.M., Haik, S., Leucht, C., Hundt, C., Rieger, R., Krasemann, S., Deslys, J.P., Dormont, D., Lasmezas, C.I. \& Weiss, S. (2001): The 37- 
$\mathrm{kDa} / 67-\mathrm{kDa}$ laminin receptor acts as the cell-surface receptor for the cellular prion protein. Embo $J$ 20:5863-5875.

Geldermann, H. (2005): Tier-Biotechnologie. Verlag Eugen Ulmer, Stuttgart 2005.

Germerodt, M., Knorr, C., Beck, J., Drögemüller, C., Williams, J.L., Habermann, F., Fries, R. \& Brenig, B. (2004): Characterization and chromosome localization of a processed pseudogene related to the bovine laminin receptor gene family. Cytogenet Genome Res 107:123-127.

Goldmann, W., Baylis, M., Chihota, C., Stevenson, E. \& Hunter, N. (2005): Frequencies of PrP gene haplotypes in British sheep flocks and the implications for breeding programmes. J Appl Microbiol 98:1294-1302.

Grindflek, E., Moe, M., Täubert, H., Simianer, H., Lien, S. \& Moen, T. (2006): Genome-wide linkage analysis of inguinal hernia in pigs using affected sib pairs. BMC Genet 7:25.

Grosso, L.E., Park, P.W. \& Mecham, R.P. (1991): Characterization of a putative clone for the 67-kilodalton elastin/laminin receptor suggests that it encodes a cytoplasmic protein rather than a cell surface receptor. Biochemistry 30:33463350 .

Hadziselimovic, F., Thommen, L., Girard, J. \& Herzog, B. (1986): The significance of postnatal gonadotropin surge for testicular development in normal and cryptorchid testes. J Urol 136:274-276.

Harris, D.A., Peters, P.J., Taraboulos, A., Lingappa, V., DeArmond, S.J. \& Prusiner, S.B. (2004): Cell Biology of Prions. In: Prusiner, S.B. (Herausgeber): Prion Biology and Diseases. Cold Spring Harbor Laboratory Press, Cold Spring Harbor, New York 2004.

Hartsough, G.R. \& Burger, D. (1965): Encephalopathy of mink. I. Epizootiologic and clinical observations. J Infect Dis 115:387-392.

Heres, S. (1976): Research results in congenital hernias of pigs. Proceedings of the Fourth International Pig Veterinary Society Congress, Iowa State University, Ames.

Heyns, C.F., Human, H.J. \& De Klerk, D.P. (1986): Hyperplasia and hypertrophy of the gubernaculum during testicular descent in the fetus. J Urol 135:1043-1047.

Heyns, C.F., Human, H.J., Werely, C.J. \& De Klerk, D.P. (1990): The glycosaminoglycans of the gubernaculum during testicular descent in the fetus. $J$ Urol 143:612-617.

Hill, A.F., Desbruslais, M., Joiner, S., Sidle, K.C., Gowland, I., Collinge, J., Doey, L.J. \& Lantos, P. (1997): The same prion strain causes vCJD and BSE. Nature 389:448-450, 526.

Horonchik, L., Tzaban, S., Ben-Zaken, O., Yedidia, Y., Rouvinski, A., Papy-Garcia, D., Barritault, D., Vlodavsky, I. \& Taraboulos, A. (2005): Heparan sulfate is a cellular receptor for purified infectious prions. J Biol Chem 280:17062-17067.

Hundt, C., Peyrin, J.M., Haik, S., Gauczynski, S., Leucht, C., Rieger, R., Riley, M.L., Deslys, J.P., Dormont, D., Lasmezas, C.I. \& Weiss, S. (2001): Identification of interaction domains of the prion protein with its $37-\mathrm{kDa} / 67-\mathrm{kDa}$ laminin receptor. Embo J 20:5876-5886.

Hutson, J.M. (1985): A biphasic model for the hormonal control of testicular descent. Lancet 2:419-421.

Hutson, J.M. \& Hasthorpe, S. (2005): Testicular descent and cryptorchidism: the state of the art in 2004. J Pediatr Surg 40:297-302. 
Hutson, J.M., Hasthorpe, S. \& Heyns, C.F. (1997): Anatomical and functional aspects of testicular descent and cryptorchidism. Endocr Rev 18:259-280.

Hutson, J.M., Watts, L.M. \& Farmer, P.J. (1998): Congenital undescended testes in neonatal pigs and the effect of exogenous calcitonin gene-related peptide. $J$ Urol 159:1025-1028.

Hutson, J.M., Albano, F.R., Paxton, G., Sugita, Y., Connor, R., Clarnette, T.D., Gray, A.Z., Watts, L.M., Farmer, P.J. \& Hasthorpe, S. (2000): In vitro fusion of human inguinal hernia with associated epithelial transformation. Cells Tissues Organs 166:249-258.

Jackers, P., Clausse, N., Fernandez, M., Berti, A., Princen, F., Wewer, U., Sobel, M.E. \& Castronovo, V. (1996): Seventeen copies of the human $37 \mathrm{kDa}$ laminin receptor precursor/p40 ribosome-associated protein gene are processed pseudogenes arisen from retropositional events. Biochim Biophys Acta 1305:98104.

Kinoshita, K., Kaneda, Y., Sato, M., Saeki, Y., Wataya-Kaneda, M. \& Hoffmann, A. (1998): LBP-p40 binds DNA tightly through associations with histones H2A, H2B, and H4. Biochem Biophys Res Commun 253:277-282.

Klonisch, T., Fowler, P.A. \& Hombach-Klonisch, S. (2004): Molecular and genetic regulation of testis descent and external genitalia development. Dev Biol 270:118.

Knap, W.B. (1986): Congenital defects inheritance of AI boars. Genetic parameters and breeding value estimation procedures. Livest. Prod. Sci. 15:337-352.

Knorr, C. (2005): Genome, Gene und molekulare Marker in der modernen Tierzucht. Habilitation, Georg-August-Universität Göttingen.

Knorr, C., Kollers, S., Fries, R. \& Brenig, B. (2002): Assignment of the CALCA/alpha-CGRP gene (CALCA) to porcine chromosome SSC2p13-->p11 by fluorescence in situ hybridization and by analysis of somatic cell and radiation hybrid panels. Cytogenet Genome Res 97:140F.

Knorr, C., Taubert, H., Peters, U. \& Brenig, B. (2004): Characterization of two SNPs (single nucleotide polymorphisms) in the porcine INSL3 gene and their exclusion as a common genetic basis of hernia inguinalis in pigs. Biochem Genet 42:11-19.

Knorr, C., Beuermann, C., Beck, J. \& Brenig, B. (2007): Characterization of the porcine multicopy ribosomal protein $\mathrm{SA} / 37-\mathrm{kDa}$ laminin receptor gene family. Gene 395:135-143.

Knorr, C., Beck, J., Beuermann, C., Chen, K., Ding, N., Gatphayak, K., Huang, L.S., Laenoi, W. \& Brenig, B. (2006): Chromosomal assignment of porcine oncogenic and apoptopic genes CACNA2D2, TUSC4, ATP2A1, COL1A1, TAC1, BAK1 and CASP9. Anim Genet 37:523-525.

Lande, R. \& Thompson, R. (1990): Efficiency of marker-assisted selection in the improvement of quantitative traits. Genetics 124:743-756.

Landowski, T.H., Uthayakumar, S. \& Starkey, J.R. (1995): Control pathways of the 67 $\mathrm{kDa}$ laminin binding protein: surface expression and activity of a new ligand binding domain. Clin Exp Metastasis 13:357-372.

Leucht, C., Simoneau, S., Rey, C., Vana, K., Rieger, R., Lasmezas, C.I. \& Weiss, S. (2003): The $37 \mathrm{kDa} / 67 \mathrm{kDa}$ laminin receptor is required for $\operatorname{PrP}(\mathrm{Sc})$ propagation in scrapie-infected neuronal cells. EMBO Rep 4:290-295.

Liu, Y. (1991): Berücksichtigung von Geburtsfehlern bei der Selektion in der Schweinezucht. Dissertation, Georg-August-Universität Göttingen. 
Lloyd, S.E., Uphill, J.B., Targonski, P.V., Fisher, E.M. \& Collinge, J. (2002): Identification of genetic loci affecting mouse-adapted bovine spongiform encephalopathy incubation time in mice. Neurogenetics 4:77-81.

Lloyd, S.E., Onwuazor, O.N., Beck, J.A., Mallinson, G., Farrall, M., Targonski, P., Collinge, J. \& Fisher, E.M. (2001): Identification of multiple quantitative trait loci linked to prion disease incubation period in mice. Proc Natl Acad Sci U S A 98:6279-6283.

Ludwig, G.V., Kondig, J.P. \& Smith, J.F. (1996): A putative receptor for Venezuelan equine encephalitis virus from mosquito cells. $J$ Virol 70:5592-5599.

Lysek, D.A., Schorn, C., Nivon, L.G., Esteve-Moya, V., Christen, B., Calzolai, L., von Schroetter, C., Fiorito, F., Herrmann, T., Guntert, P. \& Wuthrich, K. (2005): Prion protein NMR structures of cats, dogs, pigs, and sheep. Proc Natl Acad Sci U S A 102:640-645.

Manolakou, K., Beaton, J., McConnell, I., Farquar, C., Manson, J., Hastie, N.D., Bruce, M. \& Jackson, I.J. (2001): Genetic and environmental factors modify bovine spongiform encephalopathy incubation period in mice. Proc Natl Acad Sci U S A 98:7402-7407.

Manuelidis, L., Yu, Z.X., Barquero, N. \& Mullins, B. (2007): Cells infected with scrapie and Creutzfeldt-Jakob disease agents produce intracellular 25-nm viruslike particles. Proc Natl Acad Sci U S A 104:1965-1970.

Matthews, D. \& Cooke, B.C. (2003): The potential for transmissible spongiform encephalopathies in non-ruminant livestock and fish. Rev Sci Tech 22:283-296.

McGowan, J. (1922): Scrapie in sheep. Scott J Agric 5:365-375.

McKinley, M.P., Bolton, D.C. \& Prusiner, S.B. (1983): A protease-resistant protein is a structural component of the scrapie prion. Cell 35:57-62.

McMahon, D.R., Kramer, S.A. \& Husmann, D.A. (1995): Antiandrogen induced cryptorchidism in the pig is associated with failed gubernacular regression and epididymal malformations. J Urol 154:553-557.

Meuwissen, T.H., Hayes, B.J. \& Goddard, M.E. (2001): Prediction of total genetic value using genome-wide dense marker maps. Genetics 157:1819-1829.

Mikami, H. \& Fredeen, H.T. (1979): A genetic study of cryptorchidism and scrotal hernia in pigs. Can J Genet Cytol 21:9-19.

Milan, D., Jeon, J.T., Looft, C., Amarger, V., Robic, A., Thelander, M., Rogel-Gaillard, C., Paul, S., Iannuccelli, N., Rask, L., Ronne, H., Lundstrom, K., Reinsch, N., Gellin, J., Kalm, E., Roy, P.L., Chardon, P. \& Andersson, L. (2000): A mutation in PRKAG3 associated with excess glycogen content in pig skeletal muscle. Science 288: $1248-1251$.

Morel, E., Andrieu, T., Casagrande, F., Gauczynski, S., Weiss, S., Grassi, J., Rousset, M., Dormont, D. \& Chambaz, J. (2005): Bovine prion is endocytosed by human enterocytes via the $37 \mathrm{kDa} / 67 \mathrm{kDa}$ laminin receptor. Am J Pathol 167:10331042.

Moreno, C.R., Lantier, F., Lantier, I., Sarradin, P. \& Elsen, J.M. (2003a): Detection of new quantitative trait Loci for susceptibility to transmissible spongiform encephalopathies in mice. Genetics 165:2085-2091.

Moreno, C.R., Lantier, F., Berthon, P., Gautier-Bouchardon, A.V., Boivin, R., Lantier, I., Brunel, J.C., Weisbecker, J.L., Francois, D., Bouix, J. \& Elsen, J.M. (2003b): Genetic parameters for resistance to the Salmonella abortusovis vaccinal strain Rv6 in sheep. Genet Sel Evol 35:199-217. 
Morris, R.J., Parkyn, C.J. \& Jen, A. (2006): Traffic of prion protein between different compartments on the neuronal surface, and the propagation of prion disease. FEBS Lett 580:5565-5571.

Mueller, A., Knorr, C., Habermann, F., Slanchev, K., Zwilling, D., Fries, R. \& Brenig, B. (2003): Assignment of the beta- $\mathrm{N}$-acetylhexosaminidase gene (HEXB) to porcine chromosome SSC2q21-->q22 by fluorescence in situ hybridization and by analysis of somatic cell and radiation hybrid panels. Cytogenet Genome Res 101:178.

NAGRP (2007a): Animal QTLdb. http://www.animalgenome.org/QTLdb/, (aufgerufen am 10.11.2007)

NAGRP (2007b): USDA-MARC Swine Genome Map. http://www.animalgenome.org/pigs/maps/marcmap.html, (aufgerufen am 11.11.2007)

Nef, S. \& Parada, L.F. (1999): Cryptorchidism in mice mutant for Insl3. Nat Genet 22:295-299.

Nezer, C., Moreau, L., Brouwers, B., Coppieters, W., Detilleux, J., Hanset, R., Karim, L., Kvasz, A., Leroy, P. \& Georges, M. (1999): An imprinted QTL with major effect on muscle mass and fat deposition maps to the IGF2 locus in pigs. Nat Genet 21:155-156.

Ng, S.L., Bidarkar, S.S., Sourial, M., Farmer, P.J., Donath, S. \& Hutson, J.M. (2005): Gubernacular cell division in different rodent models of cryptorchidism supports indirect androgenic action via the genitofemoral nerve. J Pediatr Surg 40:434441.

Oesch, B., Westaway, D., Walchli, M., McKinley, M.P., Kent, S.B., Aebersold, R., Barry, R.A., Tempst, P., Teplow, D.B., Hood, L.E. \& et al. (1985): A cellular gene encodes scrapie PrP 27-30 protein. Cell 40:735-746.

Overbeek, P.A., Gorlov, I.P., Sutherland, R.W., Houston, J.B., Harrison, W.R., Boettger-Tong, H.L., Bishop, C.E. \& Agoulnik, A.I. (2001): A transgenic insertion causing cryptorchidism in mice. Genesis 30:26-35.

Pearson, G.R., Wyatt, J.M., Gruffydd-Jones, T.J., Hope, J., Chong, A., Higgins, R.J., Scott, A.C. \& Wells, G.A. (1992): Feline spongiform encephalopathy: fibril and PrP studies. Vet Rec 131:307-310.

Peltonen, L. (2000): Positional cloning of disease genes: advantages of genetic isolates. Hum Hered 50:66-75.

Phizicky, E.M. \& Fields, S. (1995): Protein-protein interactions: methods for detection and analysis. Microbiol Rev 59:94-123.

Plastow, G., Sasaki, S., Yu, T.B., Deeb, N., Prall, G., Siggens, K. \& Wilson, E. (2003): Practical Application of DNA Markers for Genetic Improvement. National Swine Improvement Federation Conference and Annual Meeting, Des Moines, Iowa, USA, NSIF.

Prusiner, S.B. (1982): Novel proteinaceous infectious particles cause scrapie. Science 216:136-144.

Prusiner, S.B. (1991): Molecular biology of prion diseases. Science 252:1515-1522.

Prusiner, S.B. (2004): An Introduction to Prion Biology and Diseases. In: Prusiner, S.B. (Herausgeber): Prion Biology and Diseases. Cold Spring Harbor Laboratory Press, Cold Spring Harbor, New York 2004.

Rao, C.N., Castronovo, V., Schmitt, M.C., Wewer, U.M., Claysmith, A.P., Liotta, L.A. \& Sobel, M.E. (1989): Evidence for a precursor of the high-affinity metastasisassociated murine laminin receptor. Biochemistry 28:7476-7486. 
Rieger, R., Lasmezas, C.I. \& Weiss, S. (1999): Role of the $37 \mathrm{kDa}$ laminin receptor precursor in the life cycle of prions. Transfus Clin Biol 6:7-16.

Rieger, R., Edenhofer, F., Lasmezas, C.I. \& Weiss, S. (1997): The human 37-kDa laminin receptor precursor interacts with the prion protein in eukaryotic cells. Nat Med 3:1383-1388.

Riek, R., Hornemann, S., Wider, G., Billeter, M., Glockshuber, R. \& Wuthrich, K. (1996): NMR structure of the mouse prion protein domain $\operatorname{PrP}(121-321)$. Nature 382:180-182.

Rijli, F.M., Matyas, R., Pellegrini, M., Dierich, A., Gruss, P., Dolle, P. \& Chambon, P. (1995): Cryptorchidism and homeotic transformations of spinal nerves and vertebrae in Hoxa-10 mutant mice. Proc Natl Acad Sci U S A 92:8185-8189.

Risch, N. \& Merikangas, K. (1996): The future of genetic studies of complex human diseases. Science 273:1516-1517.

Risch, N.J. (2000): Searching for genetic determinants in the new millennium. Nature 405:847-856.

Rosenfeld, M.G., Mermod, J.J., Amara, S.G., Swanson, L.W., Sawchenko, P.E., Rivier, J., Vale, W.W. \& Evans, R.M. (1983): Production of a novel neuropeptide encoded by the calcitonin gene via tissue-specific RNA processing. Nature 304:129-135.

Rothschild, M.F., Hu, Z.L. \& Jiang, Z. (2007): Advances in QTL mapping in pigs. Int J Biol Sci 3:192-197.

Satokata, I., Benson, G. \& Maas, R. (1995): Sexually dimorphic sterility phenotypes in Hoxa10-deficient mice. Nature 374:460-463.

Schook, L.B., Beever, J.E., Rogers, J., Humphray, S., Archibald, A., Chardon, P., Milan, D., Rohrer, G. \& Eversole, K. (2005): Swine Genome Sequencing Consortium (SGSC): a strategic roadmap for sequencing the pig genome. Comp Funct Genom 6:251-255.

Scott, M.R., Peretz, D., Nguyen, H.O., Dearmond, S.J. \& Prusiner, S.B. (2005): Transmission barriers for bovine, ovine, and human prions in transgenic mice. $J$ Virol 79:5259-5271.

Scott, M.R., Peretz, D., Ridley, H.F., Baker, H.F., DeArmond, S.J. \& Prusiner, S.B. (2004): Transgenetic investigations of the species barrier and prion strains. In: Prusiner, S.B. (Herausgeber): Prion Biology and Diseases. Cold Spring Harbor Laboratory Press, Cold Spring Harbor, New York 2004.

Shmakov, A.N., Bode, J., Kilshaw, P.J. \& Ghosh, S. (2000): Diverse patterns of expression of the $67-\mathrm{kD}$ laminin receptor in human small intestinal mucosa: potential binding sites for prion proteins? J Pathol 191:318-322.

Shyng, S.L., Heuser, J.E. \& Harris, D.A. (1994): A glycolipid-anchored prion protein is endocytosed via clathrin-coated pits. J Cell Biol 125:1239-1250.

Silva-Ramos, M., Oliveira, J.M., Cabeda, J.M., Reis, A., Soares, J. \& Pimenta, A. (2006): The CAG repeat within the androgen receptor gene and its relationship to cryptorchidism. Int Braz J Urol 32:330-334; discussion 335.

Somerville, R.A. (2002): TSE agent strains and PrP: reconciling structure and function. Trends Biochem Sci 27:606-612.

Stahl, N., Borchelt, D.R., Hsiao, K. \& Prusiner, S.B. (1987): Scrapie prion protein contains a phosphatidylinositol glycolipid. Cell 51:229-240.

Tanyel, F.C. (2004): Obliteration of processus vaginalis: aberrations in the regulatory mechanism result in an inguinal hernia, hydrocele or undescended testis. Turk $J$ Pediatr 46 Suppl:18-27. 
Tanyel, F.C. \& Okur, H.D. (2004): Autonomic nervous system appears to play a role in obliteration of processus vaginalis. Hernia 8:149-154.

Taylor, D.R. \& Hooper, N.M. (2007): The low-density lipoprotein receptor-related protein 1 (LRP1) mediates the endocytosis of the cellular prion protein. Biochem $J$ 402:17-23.

Thomson, G. (2001): An overview of the genetic analysis of complex diseases, with reference to type 1 diabetes. Best Pract Res Clin Endocrinol Metab 15:265-277.

Tio, P.H., Jong, W.W. \& Cardosa, M.J. (2005): Two dimensional VOPBA reveals laminin receptor (LAMR1) interaction with dengue virus serotypes 1, 2 and 3. Virol J 2:25.

Tomiyama, H., Hutson, J.M., Truong, A. \& Agoulnik, A.I. (2003): Transabdominal testicular descent is disrupted in mice with deletion of insulinlike factor 3 receptor. J Pediatr Surg 38:1793-1798.

Uibeleisen, A.-C. (2001): Isolierung, Charakterisierung und molekulargenetische Analyse des porcinen HOXA10 Gens. Masterarbeit, Georg-August-Universität.

van der Werf, J. \& Kinghorn, B. (2000): Basics of Marker Assisted Selection. http://www.animalgenome.org/edu/QTL/Julius notes/16 markers.PDF, (aufgerufen am 02.12.2007)

Vana, K., Zuber, C., Nikles, D. \& Weiss, S. (2007): Novel aspects of prions, their receptor molecules, and innovative approaches for TSE therapy. Cell Mol Neurobiol 27:107-128.

Vey, M., Pilkuhn, S., Wille, H., Nixon, R., DeArmond, S.J., Smart, E.J., Anderson, R.G., Taraboulos, A. \& Prusiner, S.B. (1996): Subcellular colocalization of the cellular and scrapie prion proteins in caveolae-like membranous domains. Proc Natl Acad Sci U S A 93:14945-14949.

Vorberg, I., Groschup, M.H., Pfaff, E. \& Priola, S.A. (2003): Multiple amino acid residues within the rabbit prion protein inhibit formation of its abnormal isoform. J Virol 77:2003-2009.

Wang, K.S., Kuhn, R.J., Strauss, E.G., Ou, S. \& Strauss, J.H. (1992): High-affinity laminin receptor is a receptor for Sindbis virus in mammalian cells. $J$ Virol 66:4992-5001.

Weiss, S. (2005): Cellular Biochemistry: The prion protein receptor as a target for therapy in prion diseases. Chemie Dozenten Tagung, München, Tagungsband Chemie Dozenten Tagung.

Wells, G.A., Scott, A.C., Johnson, C.T., Gunning, R.F., Hancock, R.D., Jeffrey, M., Dawson, M. \& Bradley, R. (1987): A novel progressive spongiform encephalopathy in cattle. Vet Rec 121:419-420.

Wells, G.A., Hawkins, S.A., Austin, A.R., Ryder, S.J., Done, S.H., Green, R.B., Dexter, I., Dawson, M. \& Kimberlin, R.H. (2003): Studies of the transmissibility of the agent of bovine spongiform encephalopathy to pigs. J Gen Virol 84:1021-1031.

Wensing, C.J. (1986): Testicular descent in the rat and a comparison of this process in the rat with that in the pig. Anat Rec 214:154-160.

Wensing, C.J. (1988): The embryology of testicular descent. Horm Res 30:144-152.

Wilesmith, J.W., Wells, G.A., Cranwell, M.P. \& Ryan, J.B. (1988): Bovine spongiform encephalopathy: epidemiological studies. Vet Rec 123:638-644.

Williams, E.S. \& Young, S. (1980): Chronic wasting disease of captive mule deer: a spongiform encephalopathy. $J$ Wildl Dis 16:89-98.

Williams, M.P.L. \& Hutson, J.M. (1991): The phylogeny of testicular descent. Pediatr Surg Int 6:162-166. 
Wu, R., Ma, C.X. \& Casella, G. (2002): Joint linkage and linkage disequilibrium mapping of quantitative trait loci in natural populations. Genetics 160:779-792.

Wüthrich, K. (1990): Protein structure determination in solution by NMR spectroscopy. J Biol Chem 265:22059-22062.

Yow, H.K., Wong, J.M., Chen, H.S., Lee, C.G., Davis, S., Steele, G.D., Jr. \& Chen, L.B. (1988): Increased mRNA expression of a laminin-binding protein in human colon carcinoma: complete sequence of a full-length cDNA encoding the protein. Proc Natl Acad Sci U S A 85:6394-6398.

Zimmermann, S., Steding, G., Emmen, J.M., Brinkmann, A.O., Nayernia, K., Holstein, A.F., Engel, W. \& Adham, I.M. (1999): Targeted disruption of the Insl3 gene causes bilateral cryptorchidism. Mol Endocrinol 13:681-691. 


\subsubsection{Danksagung}

Ich bedanke mich besonders bei Herrn Prof. Dr. Dr. Bertram Brenig für die Überlassung des Themas und für die Betreuung meiner Dissertation. Danke natürlich auch für die Einführung in die bayerische Trinkkultur.

Weiterhin gilt mein besonderer Dank Herrn Prof. Dr. Christoph Knorr für die Betreuung und Unterstützung (auch der moralischen) und ein immer offenes Ohr.

Meinen Kollegen und Koautoren danke ich für die gute Zusammenarbeit. Besonders erwähnt sei natürlich die „Gang“, namentlich: Kirsten Bornemann-Kolatzki, Monique Germerodt, Viola Raupach, Alexandra Siebels, Frauke Mayer, Rifat Morina und Christian Beuermann.

Außerdem danke ich der Firma Chronix Biomedical und insbesondere Herrn PhD Howard Urnovitz und Herrn Dr. Ekkehard Schütz dafür, dass ich meine Dissertation neben der Tätigkeit bei der Firma Chronix abschließen konnte und für das entgegengebrachte Vertrauen. Herrn Dr. Ekkehard Schütz danke ich zudem für seine geduldige Hilfe in allen statistischen Fragestellungen und seinen Einsatz als Testhörer.

Natürlich hätte ich es ohne das „Super-Team Chronix“ nie und nimmer geschafft, deshalb ein Riesendanke an Sara Henneke und Stefan Balzer.

Zuletzt möchte ich mich bei meiner Familie bedanken, meinen Eltern Carola und Volker Beck und meinem Bruder Janosch, die mich immer unterstützt haben. Und danke auch Dir, Kilian,...für alles. 